\title{
Respiratory Implications of Pediatric Neuromuscular Disease
}

\author{
Howard B Panitch MD
}

\author{
Introduction \\ Airway Clearance and Lung Defense \\ Methods to Enhance Airway Clearance \\ Manually Assisted Cough \\ Mechanical Insufflation-Exsufflation \\ Methods to Mobilize Secretions \\ High-Frequency Chest-Wall Compressions \\ Intrapulmonary Percussive Ventilation \\ Medications That Alter Mucociliary or Cough Clearance \\ Sleep Problems in Children With Neuromuscular Disorders \\ Epidemiology of Sleep-Disordered Breathing \\ Evaluation of Sleep-Disordered Breathing \\ Ventilatory Support for Children With NMD \\ The Impact of Ventilatory Support in NMDs \\ When to Institute Ventilatory Support \\ Noninvasive Ventilation Versus Ventilation via Tracheostomy \\ Summary
}

Children with progressive neuromuscular weakness undergo a stereotypical progression of respiratory involvement, beginning with impaired airway clearance and progressing to nocturnal and then diurnal ventilatory failure. This review examines issues related to airway clearance and mucus mobilization, sleep problems, and use of assisted ventilation in children with neuromuscular diseases. Interventions for each of these problems have been created or adapted for the pediatric population. The use of airway clearance therapies and assisted ventilation have improved survival of children with neuromuscular weakness. Questions regarding the best time to introduce some therapies, the therapeutic utility of certain interventions, and the cost-effectiveness of various treatments demand further investigation. Studies that assess the potential to improve quality of life and reduce hospitalizations and frequency of lower-respiratory tract infections will help clinicians to decide which techniques are best suited for use in children. As children with neuromuscular disease survive longer, coordinated programs for transitioning these patients to adult care must be developed to enhance their quality of life. Key words: airway clearance therapies; mechanical in-exsufflator; intrapulmonary percussive ventilation; high-frequency chest-wall compressions; sleep-disordered breathing; noninvasive ventilation. [Respir Care 2017;62(6):826-848. @ 2017 Daedalus Enterprises]

\section{Introduction}

Children with progressive neuromuscular weakness undergo a stereotypical progression of respiratory involve-

\footnotetext{
Dr Panitch is affiliated with the Department of Pediatrics, Perelman School of Medicine, University of Pennsylvania, and the Division of Pulmonary Medicine, Children's Hospital of Philadelphia, Philadelphia, Pennsylvania.
}

Dr Panitch discloses a relationship with Philips Respironics. ment (Fig. 1). ${ }^{1}$ Weakness that involves inspiratory, bulbar, or expiratory muscles can lead to the inability to take deep breaths and to cough effectively., ${ }^{2,3}$ An inability to clear secretions effectively from the airways predisposes patients with neuromuscular disease (NMD) to recurrent or chronic atelectasis and pneumonia. This, in turn, can re-

Dr Panitch presented a version of this paper at the 55th Respiratory Care Journal Conference, "Pediatric Respiratory Care" held June 10-11, 2016, in St Petersburg, Florida. 


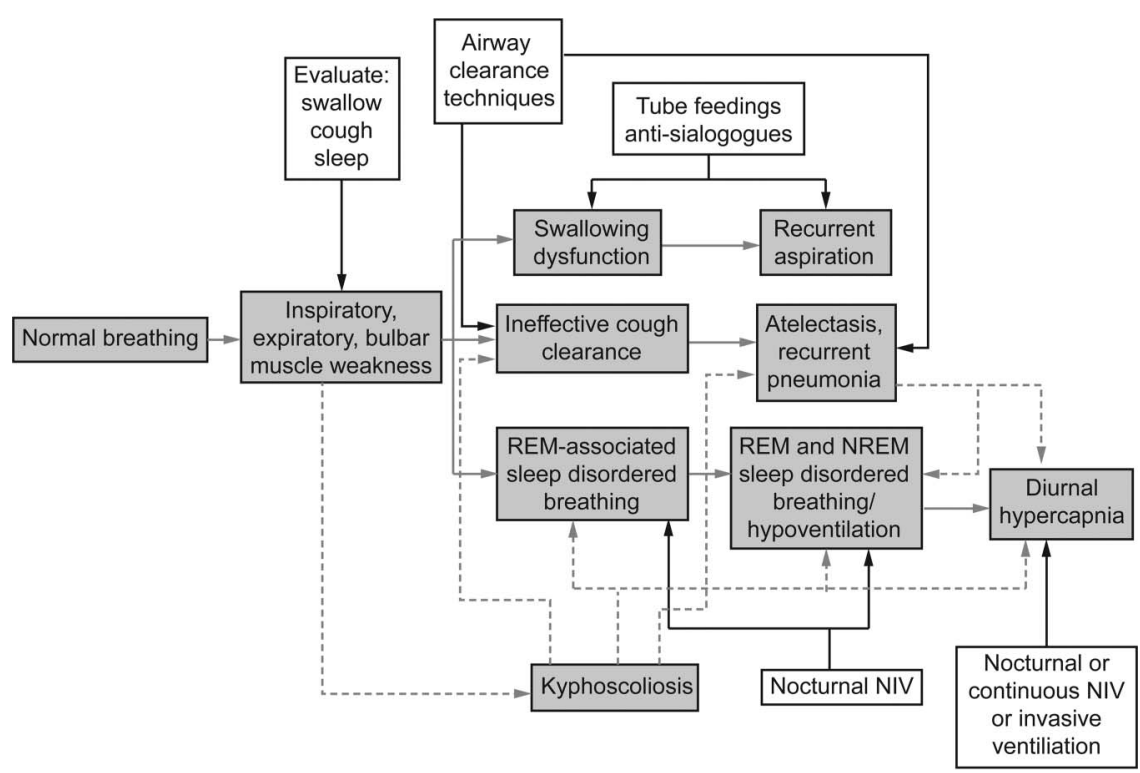

Fig. 1. Algorithm of the typical evolution of disease in patients with progressive neuromuscular disorders (gray boxes) and assessments and interventions that are considered as a function of disease status (white boxes). The presence of kyphoscoliosis can exacerbate the effects of respiratory and bulbar muscle weakness on airway clearance and ventilation (dotted lines). See text for further details. REM = rapid eye movement, NREM = non-REM, NIV = noninvasive ventilation.

duce lung compliance, increase airway resistance, and increase ventilatory demands, resulting in an imbalance between the capabilities of the respiratory pump (the chestwall and respiratory muscles) and the load imposed upon it. ${ }^{3}$ In the absence of acute illness, the first signs of respiratory insufficiency occur during sleep, when skeletal muscle tone is generally decreased and episodic generalized atony during rapid eye movement (REM) sleep occurs. ${ }^{1}$ This leads to arousals, obstructive apneas and hypopneas, sleep fragmentation, poor sleep quality, and, eventually, sleep hypoventilation. As inspiratory muscle weakness progresses, diurnal hypoventilation ensues.

Although this progression of problems is fairly predictable, the timing will vary, depending on the type of NMD and the age of the patient. For instance, an infant with spinal muscular atrophy type I (SMA I) would be expected to experience all of these problems within the first year of life, whereas a boy with Duchenne muscular dystrophy (DMD) probably would not begin to have such difficulties until his second decade of life. Children with other forms of NMD like cerebral palsy or spinal cord injury will also follow different time courses, but in the absence of inter-

\footnotetext{
Correspondence: Howard B Panitch MD, Division of Pulmonary Medicine, Children's Hospital of Philadelphia, 11054 Colket Translational Research Building, 3501 Civic Center Boulevard, Philadelphia, PA 19104. E-mail: panitch@email.chop.edu.
}

DOI: $10.4187 /$ respcare 05250 ventions, they will also experience similar problems if their underlying diseases cause respiratory muscle weakness. This review will focus on 3 care concerns that are common to children with a variety of NMDs: (1) impaired airway clearance; (2) the impact of respiratory muscle weakness on sleep; and (3) the role of noninvasive ventilation (NIV) in improving morbidity, mortality, and quality of life.

\section{Airway Clearance and Lung Defense}

Under normal circumstances, the lungs are cleared of particulate matter and infectious agents by 2 mechanisms: the mucociliary escalator and cough. Mucociliary clearance is considered to be the major method by which debris is removed from the peripheral airways, whereas cough is primarily responsible for clearing the central airways. ${ }^{4}$ The effects of mucociliary clearance are enhanced by the normal respiratory variation in airway caliber: Narrowing of the intrathoracic airways on exhalation during normal tidal breathing results in a cephalad air-flow bias that increases expiratory air-flow velocity and movement of mucus toward the mouth. ${ }^{5}$ Chronic breathing at low tidal volumes, with smaller variations in airway caliber and lower expiratory flows, could therefore potentially reduce the effectiveness of the mucociliary escalator. Additionally, chronic aspiration related to bulbar dysfunction could damage airway-lining cells and impair mucociliary clearance.

A normal cough begins with a deep inspiration of a variable volume of air. This maneuver not only increases airway diameter, but it also places the expiratory muscles 
on a favorable position of their length-tension curve, increases elastic recoil of the lung to provide greater driving pressure, and causes the chest wall to recoil inward toward its resting volume, thereby contributing potential energy to the ensuing cough maneuver. The glottis then closes for about $200 \mathrm{~ms}$ while the expiratory muscles contract, resulting in a rapid increase in intrathoracic pressure to about $100 \mathrm{~cm} \mathrm{H}_{2} \mathrm{O}$. The glottis then actively opens, and air is expulsed at rates that briefly exceed maximal flow as central airways are compressed and temporarily narrowed. ${ }^{6}$ The high linear velocity of air flow results in shearing forces at the air-mucus interface and clearance of secretions from the central airways. ${ }^{2}$ Impairment of any phase of cough can have deleterious effects on clearance of secretions from central airways: inspiratory muscle weakness will limit pre-cough inspiration and volume-dependent flow velocity; bulbar dysfunction (whether from neurological disease or the presence of a tracheostomy) will impair the compressive phase of cough; and expiratory muscle weakness will diminish the velocity of expiratory air flow.

Clinicians have sought to determine whether there are measurements of lung or respiratory muscle function that would predict who would require assistance with airway clearance. Bach and Saporito ${ }^{7}$ assessed factors that would predict successful removal of endotracheal or tracheostomy tubes in 49 adult subjects with primarily neuromuscular ventilatory insufficiency. Of all factors considered, only the ability of subjects to generate a cough peak flow $>160 \mathrm{~L} / \mathrm{min}$ with assisted or unassisted cough predicted successful extubation or decannulation, because secretion retention necessitated reinsertion of tubes to provide for airway suctioning in those with lower cough peak flows. Another study showed that the ability to generate cough flow transients, the supramaximal spikes that occur when the central airways are compressed during the cough maneuver, was present only when subjects could generate a maximum expiratory pressure $\left(\mathrm{P}_{\mathrm{Emax}}\right) \geq 60 \mathrm{~cm} \mathrm{H}_{2} \mathrm{O} .{ }^{8}$ Recognizing that some acute viral respiratory illnesses can cause a transient reduction in respiratory muscle strength in both healthy individuals ${ }^{9}$ and in patients with NMD, ${ }^{10}$ Tzeng and Bach $^{11}$ reported that in their experience, when subjects could not generate a cough peak flow $>270 \mathrm{~L} / \mathrm{min}$ when well, they were likely to produce cough peak flows $<160 \mathrm{~L} / \mathrm{min}$ during acute respiratory illnesses. In a previous report of a protocol to minimize pulmonary morbidity among 24 young adults with DMD, Bach et al ${ }^{12}$ reported that none of the subjects who could generate a cough peak flow $>270 \mathrm{~L} / \mathrm{min}$ experienced episodes of respiratory distress. Despite being based on a small number of subjects, a value of $270 \mathrm{~L} / \mathrm{min}$ for cough peak flow or a $\mathrm{P}_{\text {Emax }}$ of $60 \mathrm{~cm} \mathrm{H}_{2} \mathrm{O}$ are widely accepted as cutoff values to determine when adolescents or adults should receive assistance with coughing. ${ }^{13,14}$ In some European countries, a cough peak flow of $180 \mathrm{~L} / \mathrm{min}$ has been proposed as the threshold value for an effective cough. ${ }^{15}$

These thresholds, however, are inappropriate for children under the age of $12 \mathrm{y}$. The airways of young children are more compliant than those of older children and thus can narrow or collapse at lower transmural pressures. ${ }^{16}$ Thus, younger children can probably generate supramaximal flow transients using lower expiratory pressures. Normal values for cough peak flow, like peak expiratory flow or other forced flow measurements, change with age and height. There are few normative data for cough peak flow in healthy children. In 649 children between 4 and 18 y old, the 5th percentile for cough peak flow was $270 \mathrm{~L} / \mathrm{min}$ or less in both boys and girls through $10 \mathrm{y}$ of age. ${ }^{17}$ Since those children did not have histories of recurrent lower-respiratory tract infections, it seems clear that lower cough peak flow in young children is adequate to clear the airways of secretions. In infants, increased airway compliance coupled with a pulmonary elastic recoil pressure that is lower than in adults combine to reduce cough peak flow ${ }^{6}$; when during childhood or adolescence these factors change to approach adult values remains unknown. At present, the best indicators for whether a young child with NMD requires assistance with cough are a history of recurrent pneumonias or the qualitative assessment of a weak cough. ${ }^{18}$

\section{Methods to Enhance Airway Clearance}

A variety of techniques have been developed to help patients with NMD clear the airways of secretions. For those patients with inspiratory muscle weakness, manual insufflation with a self-inflating bag, or mechanical insufflation with a ventilator or other positive-pressure device can be used to raise lung volume close to the vital capacity. By so doing, elastic recoil of the lung and chest wall can be used to augment expiratory muscle contraction to generate effective expiratory flow. Glossopharyngeal breathing or "frog breathing" is another effective method to raise lung volume and enhance cough clearance, ${ }^{19}$ but it is probably not a method that can be readily taught to a young child. Expiratory muscle function can be augmented manually with appropriately timed chest-wall or upperabdominal thrusts as the patient volitionally coughs, ${ }^{20,21}$ or mechanically with the use of exsufflation with negative pressure. ${ }^{22}$ These techniques effectively clear the central airways of secretions but may be ineffective at mobilizing secretions from more peripheral airways. As a result, various mucus-mobilization techniques like intrapulmonary percussive ventilation ${ }^{23-25}$ and high-frequency chest-wall compressions (HFCWC) ${ }^{26-28}$ have been used to enhance the movement of secretions from the peripheral to the more central airways where they can then be coughed out or suctioned. Investigators have also tried altering the properties of mucus to make it easier for the patient to cough 
secretions out with a variety of inhaled medications, especially when secretion retention leads to lobar atelectasis. ${ }^{29-32}$ There are few clinical trials that have been conducted to support most of these techniques, despite their widespread use among patients with NMD. ${ }^{33}$

Several of these methods have been shown to increase cough peak flow effectively in both children and adults. ${ }^{34,35}$ Among 21 ventilator-dependent adults with a variety of NMDs, cough peak flow was compared under conditions of unassisted coughing, coughing after mechanical breathstacking or glossopharyngeal breathing with or without a subsequent manually assisted cough, and with the use of mechanical in-exsufflation (MI-E). ${ }^{34}$ All methods of cough augmentation increased cough peak flow above that obtained during unassisted cough, but cough peak flow was greatest with the use of MI-E, whereas cough peak flow resulting from the use of manually assisted cough after breath-stacking was significantly higher than that achieved by breath-stacking alone. A similar study was conducted among 19 subjects with NMDs, 8 of whom were between the ages of 10 and $16 \mathrm{y} .{ }^{35}$ When comparing unassisted cough with cough assisted by physiotherapy (without prior breath-stacking), cough after breath-stacking, cough following exsufflation with negative pressure, and cough following MI-E, cough peak flow was greatest in both adult and pediatric groups following MI-E, although the pressures used for both insufflation and exsufflation were quite low. Among the pediatric subjects, no other technique significantly increased cough peak flow over that achieved during unassisted cough.

The presence of bulbar dysfunction can alter the effectiveness of some of these techniques, since glottic closure to breath-stack and attain maximum inspiratory capacities above the vital capacity may not be possible. ${ }^{36}$ Nevertheless, among 16 adults with amyotrophic lateral sclerosis in whom cough peak flow was measured unassisted and with several different interventions, all techniques that provided any type of breath-stacking produced higher cough peak flow than those involving coaching with or without manually assisted cough, independent of bulbar function. ${ }^{37} \mathrm{In}$ addition, no statistically significant differences existed between cough peak flows generated by any technique among those with versus without bulbar dysfunction. Furthermore, the authors noted that in any particular subject, MI-E was not always the best tool, and they cautioned that testing an array of techniques would be important in determining an airway clearance regimen for a particular patient.

\section{Manually Assisted Cough}

A manually assisted cough or quad cough involves the application of chest-wall or abdominal thrusts by a caregiver in synchrony with a patient's cough to augment or replace expiratory muscle activity. The effectiveness of this therapy depends heavily on the skill of the caregiver to apply adequate pressure and also to be able to synchronize the thrust with the patient's cough effort. ${ }^{38}$ Often, manually assisted cough is combined with breath-stacking to enhance cough peak flow over that achieved with manually assisted cough alone. ${ }^{15,39,40}$ Whereas breath-stacking can be accomplished with glossopharyngeal breathing or a manual resuscitation bag with or without a one-way valve, it can also be performed with a bi-level pressure generator or mechanical ventilator. Use of a manual resuscitation bag typically requires the assistance of a second caregiver to deliver the breath while the first caregiver applies abdominal or thoracic expiratory thrusts. Among 52 adults with DMD, manual insufflation was equivalent to use of a mechanical ventilator in increasing cough peak flow over unassisted cough peak flow values. ${ }^{41}$ There are, however, limits to the effectiveness of manually assisted cough and manually assisted cough with breath-stacking. Chest-wall distortion and scoliosis can reduce the usefulness of manually assisted cough, and the frequency at which manually assisted cough is required during acute illnesses can cause caregiver fatigue.

Certain physiologic measurements can also predict which patients would benefit from manually assisted cough augmentation techniques. Measurements of cough peak flow along with $\mathrm{P}_{\mathrm{Emax}}$ and vital capacity (VC) were collected in 179 adolescents and adults with NMD at baseline, after breath-stacking, and after breath-stacking plus manually assisted cough. ${ }^{15}$ There was an inverse relationship between improvement in cough peak flow with any cough augmentation technique and the baseline VC: although there was no VC upper limit of effectiveness for manually assisted cough, improvements with cough augmentation decreased linearly with increasing $\mathrm{VC}$ and $\mathrm{P}_{\text {Emax }}$. Thus, application of manually assisted cough would be unlikely to enhance cough peak flow if the baseline $\mathrm{VC}$ were $>1,910 \mathrm{~mL}$ or if the $\mathrm{P}_{\text {Emax }}$ were $>34 \mathrm{~cm} \mathrm{H}_{2} \mathrm{O}$. There was also a VC below which manually assisted cough without breath-stacking $(558 \mathrm{~mL})$ or manually assisted cough plus breath-stacking $(304 \mathrm{~mL})$ would be unlikely to produce an effective cough peak flow. Similarly, if the $\mathrm{P}_{\text {Emax }}$ were $<14 \mathrm{~cm} \mathrm{H}_{2} \mathrm{O}$, it would be improbable for a patient to achieve an effective cough peak flow with manually assisted cough techniques. In these latter situations, use of a mechanical in-exsufflator was recommended to avoid complications of secretion retention. ${ }^{15}$

\section{Mechanical Insufflation-Exsufflation}

If baseline lung function, ${ }^{15}$ severe chest-wall distortion, or an unstable chest wall precludes the use of manually assisted cough, MI-E can be used to produce an effective cough peak flow. MI-E involves passive lung expansion with the use of a positive-pressure insufflation followed rapidly by exsufflation with negative pressure to produce 
an expiratory flow velocity high enough to shear secretions from the airway wall and move them toward the airway opening, where they can be expectorated or suctioned. ${ }^{42}$ The MI-E device can be used via face mask or mouthpiece or attached directly to a tracheostomy or endotracheal tube. ${ }^{43}$

Insufflation and exsufflation pressures and duration of pressure application are set independently according to patient comfort and effectiveness. In a review of MI-E use in 62 subjects with NMD ranging in age from 3 months to $28.6 \mathrm{y}$, Miske et $\mathrm{al}^{43}$ found no correlation between the pressures used and either subject age or the type of underlying NMD. Using MI-E with a lung model set to simulate normal adult lung mechanics, Gómez-Merino et $\mathrm{al}^{44}$ assessed the effects of altering insufflation and exsufflation pressures and insufflation to exsufflation times on resulting lung volumes, pressures, and flows. Whereas they noted that MI-E settings in practice must be individualized, they observed that in their lung model, effective cough peak flows $>2.7 \mathrm{~L} / \mathrm{s}$ did not occur with pressure spans $<30 \mathrm{~cm} \mathrm{H}_{2} \mathrm{O}$. Further, increasing insufflation times resulted in significantly greater exsufflation flows, whereas lengthening exsufflation time did not increase exsufflation flow. Subsequently, the same group varied compliance and resistance of the lung model and showed that alteration in respiratory system mechanics, including decreased compliance or increased resistance, would require increased insufflation and exsufflation pressures to achieve adequate precough volumes and cough peak flows. ${ }^{45}$ The authors cautioned that in such situations, patients would require higher MI-E pressures to achieve adequate cough peak flows. Underlining that point, Miske et $\mathrm{al}^{43}$ reported that $39 \%$ of subjects were instructed to increase pressure settings during periods of illness to remove secretions more effectively.

Individualization of pressure and time settings for MI-E is important not only because of the effects of alteration of lung mechanics on cough peak flow, but also because of inherent differences in machines. A bench study that compared 5 devices for their accuracy in delivering set pressures and set times to a lung model disclosed discrepancies in most MI-E models tested. ${ }^{46}$ The investigators also found inconsistencies in the pressures delivered and their duration between different devices of the same model of in-exsufflator. Furthermore, the performance of each of the models was affected differently by alterations in lung mechanics and imposed leaks. The authors cautioned that the different MI-E devices are not interchangeable and that settings should be targeted for each patient with the actual machine to be used.

Because recommendations for MI-E settings in infants and children who require tracheostomies are lacking and patient data are sparse, Striegl et $\mathrm{al}^{47}$ used a lung model simulating normal lung mechanics of a 6- and 10-kg infant and assessed the effects of altering MI-E pressures and duration of insufflation and exsufflation delivered via 3.0-, 3.5-, and 4.0-mm inner diameter tracheostomy interfaces.
With all tracheostomy tubes studied, an insufflation time of $1 \mathrm{~s}$ was required for pressure equilibration across the tube. Additionally, an inspiratory volume $>70 \%$ of the calculated VC was achieved at all insufflation pressures with an insufflation time of $1 \mathrm{~s}$. Maximum expiratory flow, a surrogate for cough peak flow, increased with increasing insufflation time, insufflation pressure, and exsufflation pressure, but not with increasing exsufflation time. Expiratory pressure had a greater effect on maximum expiratory flow than did inspiratory pressure, and the authors reasoned that secretion clearance could be enhanced with greater pressure differentials between insufflation and exsufflation by using asymmetric settings (eg, $+20 /-30 \mathrm{~cm} \mathrm{H}_{2} \mathrm{O}$ ). They also emphasized that insufflation pressures as low as $20 \mathrm{~cm} \mathrm{H}_{2} \mathrm{O}$ achieved adequate pre-cough lung volumes. The authors cautioned, however, that primary safety concerns regarding the use of MI-E in infants include the risk of barotrauma, central airway collapse with high exsufflation pressures, and loss of FRC with prolonged exsufflation times.

The risk for barotrauma with MI-E use is real, but complications like pneumothorax are extremely rarely reported in adults, ${ }^{48}$ and none have been reported in children. The author has, however, cared for a 16-y-old boy with DMD who experienced recurrent pneumothoraces with the use of MI-E and positive-pressure ventilation via tracheostomy. Rupture of a tympanic membrane was also described in a 19-y-old patient with DMD who used both MI-E and positive-pressure NIV. ${ }^{49}$ Treatment included both temporary cessation of use of MI-E and a reduction in inflating pressures of his noninvasive ventilator. Dynamic airway collapse has been reported in adults with bulbar dysfunction during the exsufflation cycle of MI-E use, ${ }^{22,50}$ and use of a coordinated abdominal thrust has been advocated as a means to avoid airway collapse during exsufflation. ${ }^{22}$ Using transnasal flexible laryngoscopy to study the laryngeal response to MI-E use in healthy young adults, Andersen et $\mathrm{al}^{51}$ found that application of a negative pressure during exsufflation produced muscular and/or reflex responses that caused hypopharyngeal constriction. These investigators also found that the epiglottis often retroflexed during insufflation, causing intermittent airway obstruction and potentially limiting the effectiveness of insufflation. This certainly would be a concern when using MI-E in a subject who also has significant laryngomalacia. Other reported complications of MI-E use, like cardiac dysrhythmias, aggravation of gastroesophageal reflux, hemoptysis, or abdominal distention and discomfort, are uncommon or have never been reported in children with NMDs. ${ }^{42,43}$ The intraabdominal pressure generated with MI-E use was $51 \pm 32 \%$ of the set insufflation pressure among 13 children with NMDs, and lower than the measured gastric pressure during spontaneous cough in 1 of the 3 subjects who could also generate a spontaneous cough..$^{52}$ These data suggest 
that MI-E use should be safe in the immediate postoperative period, even for children who require upper-abdominal surgery (ie, gastrostomy tube placement).

A Cochrane review ${ }^{53}$ concluded that existing data are insufficient to recommend MI-E use for patients with NMD, principally because most studies report short-term effects of a single MI-E treatment, and there are not long-term studies examining survival, length of hospital stay, quality of life, or serious adverse effects related to MI-E use. However, there have been several small non-randomized trials that address some of these issues. Vianello et al ${ }^{54}$ compared the short-term outcomes of 11 consecutive subjects with NMD admitted to the ICU during an acute lower-respiratory-tract infection and treated with MI-E in addition to conventional chest physiotherapy with outcomes of 16 historical matched controls who received chest physiotherapy alone. Treatment failure, defined as need for cricothyroid minitracheostomy or endotracheal intubation, was significantly less among the group receiving MI-E compared with controls. There were, however, no differences in duration of hospitalization, time spent receiving mechanical ventilation, or proportion of subjects who required bronchoscopically assisted removal of secretions between the 2 groups. Chatwin and Simonds ${ }^{55}$ assessed the addition of MI-E to chest physiotherapy followed by manually assisted cough during an acute respiratory illness in 8 subjects 4-44 y old. The addition of MI-E to the airway clearance regimen significantly shortened the duration of airway clearance sessions, but subjects felt more fatigued after MI-E use than when no MI-E was employed, perhaps because of long exsufflation times.

Two studies from Western Australia surveyed families of children with NMD who used an MI-E device at home. ${ }^{56,57}$ The first, involving 10 subjects $1.4-18.1$ y old, also involved a retrospective chart review. ${ }^{56}$ Among 7 of the subjects for whom there was adequate duration of observation before and after MI-E use, there was a significant reduction in number of days in the hospital at 6 and 12 months after institution of MI-E compared with the same time frame before its use. There was also a nearly statistically significant reduction in number of ICU days after MI-E use but no significant reduction in number of hospitalizations. Nevertheless, 9 of 10 parents reported that MI-E use enhanced or improved their child's quality of life and emphasized their perception that MI-E use often allowed the child to stay at home for treatments during acute respiratory illnesses. The second survey and database review involved 37 subjects 1-59 y of age (mean $19.8 \mathrm{y}$ ) who used an MI-E device for 0.1-4.0 y..$^{57}$ Of the subjects or parents, $>90 \%$ were satisfied with home use of the MI-E, and $88 \%$ agreed that the device improved their/their child's quality of life. Home use of an MI-E device was significantly associated with fewer emergency room visits (relative risk $=1.76,95 \%$ CI $1.10-2.84$ ), but there were no statistically significant reductions in hospitalizations or length of hospital stay resulting from MI-E use during the observation period. Echoing the generally positive attitude of children and their families toward home MI-E use, Moran et al ${ }^{58}$ interviewed 8 parents and 3 children with NMD who had used an MI-E at home for $\geq 3 \mathrm{y}$. They expressed feelings of improved ability to manage the child's life and to have fewer lifestyle disruptions because of their ability to intervene during crises without having to go to the hospital. There were minimal negative impacts on patients and families, mostly related to their viewing the use of the MI-E as an acknowledgment of progression of the child's disease. Most negative sentiments were offset by parents' sense of empowerment that the device gave them.

In summary, MI-E effectively increases cough peak flow and is especially helpful when other cough augmentation techniques are technically not practicable. Whether MI-E is superior to other techniques of airway clearance or not when outcomes like frequency of hospitalization, length of stay, and overall survival are considered remains to be answered. Additionally, recognition of patient characteristics that would identify who would have less favorable responses to MI-E use are needed to optimize airway clearance regimens for children with NMDs.

\section{Methods to Mobilize Secretions}

Coughing clears the central airways of debris, but occasionally secretions obstruct more peripheral airways, or acute illnesses overwhelm the ability of the mucociliary escalator to clear peripheral airways of secretions. In those situations, a variety of techniques have been used to mobilize secretions from the peripheral to the more central airways, where they can then be coughed out or suctioned. These include intrapulmonary percussive ventilation, high frequency chest-wall compression, and the use of medications to alter the properties of secretions.

\section{Intrapulmonary Percussive Ventilation}

Intrapulmonary percussive ventilation (IPV) provides low-amplitude bursts of air at frequencies in the range of $50-550$ cycles/min, with pressures of $5-35 \mathrm{~cm} \mathrm{H}_{2} \mathrm{O}$ superimposed on the patient's own breathing frequency. The percussions of gas are applied to the airways using a mouthpiece, face mask, or artificial airway (endotracheal or tracheostomy tube). They are delivered continuously through a sliding Venturi device called a Phasitron, powered with compressed gas at pressures of $20-40$ psi. The oscillations cause airway walls to vibrate in synchrony, loosening secretions. The device not only provides a mechanical means for mobilization of secretions, but it also enables simultaneous delivery of medications like bronchodilators or hy- 
pertonic saline via entrainment through the Phasitron. The intrapulmonary percussive ventilator was developed in $1979^{59}$ and received FDA clearance in 199360; its first use in children occurred in the early 1990s. ${ }^{23,61,62}$

The mechanisms by which IPV clears the airways of secretions have not been well-studied, but the device is purported to dilate airways both mechanically via a constant distending pressure as well as through the positivepressure oscillations, and pharmacologically when bronchodilators are administered. It must be cautioned, however, that drug delivery to the lung via IPV is inferior to that achieved by jet nebulization because IPV creates a smaller particle (about $0.2 \mu \mathrm{m}$ vs $2 \mu \mathrm{m}$ ) to be nebulized and delivers the drug at much higher flows compared with jet nebulization. ${ }^{63,64}$ On inspiration, the high-frequency oscillations cause pulmonary expansion and allow gas to fill distal lung units beyond accumulated airway secretions. ${ }^{60}$ Additionally, like other high-frequency oscillatory techniques, IPV may augment mucus-air flow interactions. ${ }^{25}$ By prolonging the inspiratory phase of the percussions, expiratory flow becomes greater than peak inspiratory flow, and an expiratory flow bias is created. ${ }^{25,65}$ The asymmetry of air flow accompanying the oscillations is critical for mucus clearance: when artificial mucus was instilled in the airways of sheep, secretion clearance was enhanced only when expiratory flow exceeded inspiratory flow. ${ }^{66}$ The effect was further enhanced by adding postural drainage to the maneuver.

Birnkrant et $\mathrm{al}^{23}$ described the successful use of IPV in 4 patients who had persistent atelectasis or infiltrates unresponsive to conventional chest physiotherapy. Two children and an adult had neuromuscular disease, and a third child had recurrent aspiration associated with a repaired tracheoesophageal fistula. Three of the four experienced a dramatic response to the therapy, with resolution of hypoxemia within $48 \mathrm{~h}$ of starting the therapy after failing 5-9 d of chest physiotherapy with or without manually assisted cough. One boy with DMD experienced 2 episodes of third degree heart block associated with hypoxemia that was presumed to be the result of acute airway obstruction from mobilization of secretions from the peripheral to central airways. As a result, the authors cautioned that close observation of patients who are unable to clear secretions by coughing is required when using IPV.

The role of IPV in relieving atelectasis was evaluated retrospectively in hospitalized children and prospectively in a randomized, controlled trial comparing IPV with manual chest physiotherapy with postural drainage in intubated and mechanically ventilated children. ${ }^{67}$ Children in the retrospective study ranged in age from 1 month to $15 \mathrm{y}$; the authors noted that 2 infants $<3 \mathrm{~kg}$ experienced hypotension during IPV administration, so they restricted subsequent IPV use to children $>3 \mathrm{~kg}$. Those subjects in the prospective study who were treated with IPV experi- enced radiographic improvement of atelectasis, whereas those who received manual chest physiotherapy with postural drainage had no change in their chest radiographs. Additionally, the duration of treatment to resolution of the atelectasis was half as long in the IPV group compared with the chest physiotherapy/postural drainage group.

Two small trials of IPV use were conducted among subjects with NMD. Toussaint et $\mathrm{al}^{25}$ examined short-term secretion clearance as determined by sputum weight in 8 young men with DMD and tracheostomies. The 3 subjects who did not produce large amounts of secretions at baseline experienced no significant increase in secretion production when using IPV in addition to forced expiratory technique and manually assisted cough (standard therapy) compared with standard therapy alone. The 5 young men who were mucus hypersecretors, producing $>30 \mathrm{~mL} / \mathrm{d}$ of mucus, increased secretion production by $69 \%$ when IPV was added to standard therapy compared with standard therapy alone. Reardon et al ${ }^{24}$ compared IPV with incentive spirometry (IS) in preventing lower-respiratory tract infections in 18 children with NMD followed over a single respiratory virus season. None of the 9 subjects in the IPV group received antibiotics, whereas subjects in the IS group received $44 \mathrm{~d}$ of antibiotics. Similarly, 3 subjects in the IS group experienced 3 episodes of pneumonia or bacterial bronchitis, whereas none of those in the IPV group had a pulmonary infection. Furthermore, those who used IS required significantly more supplemental respiratory treatments than those who used IPV. One weakness of this study is that the comparison group used an airway clearance modality (IS) that requires inspiratory muscle strength to be effective.

\section{High-Frequency Chest-Wall Compression}

HFCWC most commonly is accomplished by an inflatable vest attached by hoses to an air pressure generator. The generator rapidly injects and withdraws small volumes of air into and out of the vest, inflating and deflating it to produce chest compressions at frequencies and pressures selected by the clinician. The frequencies typically used range between 5 and $25 \mathrm{~Hz}$; the pressure is set in arbitrary units. No special positioning or breathing techniques are required during HFCWC therapy, making it attractive for children with neurological impairment or those unable to perform such techniques because of weakness.

HFCWC at frequencies $>3 \mathrm{~Hz}$ cause cough-like shear forces on mucus and generate asymmetrical air-flow velocities that favor movement of secretions toward the mouth. ${ }^{68,69}$ In addition, high-frequency oscillation of sputum in the range of $10 \mathrm{~Hz}$ causes a reduction in its viscosity. ${ }^{70}$ Coughing clears the trachea and main bronchi of secretions, but it is not as effective in clearing secretions 
from peripheral airways..$^{71}$ In contrast, $\mathrm{HFCWC}$ at $13 \mathrm{~Hz}$ has been shown in an animal model to clear radioactive tracer particles effectively from the periphery of the lung. ${ }^{72}$ As a result, HFCWC is considered a mucus-mobilization technique that is used in tandem with cough or other mucus extraction techniques to clear the airways of secretions.

The effectiveness of HFCWC has been demonstrated in children with cystic fibrosis, ${ }^{73,74}$ but there are few studies demonstrating its effectiveness in children with NMD. Case reports support its use in critically ill infants and children with SMA, DMD, and cerebral palsy during acute illnesses. ${ }^{75-78}$ In one 5-y-old with SMA II and ARDS following respiratory syncytial virus infection, HFCWC was used as the primary method of airway clearance and was well tolerated when IPV combined with MI-E caused episodes of hypoxemia from presumed alveolar de-recruitment. ${ }^{77}$ Most case reports note how well-tolerated HFCWC is, but one 11-y-old with cerebral palsy and an ineffective cough developed acute hypoxemic respiratory failure after receiving a treatment with HFCWC, ostensibly from aspiration of secretions after they had been mobilized. ${ }^{78}$ The authors cautioned that assistive coughing devices or techniques might be required in addition to use of HFCWC when patients have ineffective cough.

Small studies in children with a variety of neuromuscular or neurological diseases have compared health-care utilization before and after HFCWC use. ${ }^{26-28,79}$ Seven subjects with quadriplegic cerebral palsy demonstrated a significant reduction in episodes of pneumonia and more effective airway suctioning, defined as suctioning attempts in which sputum was recovered, in the 12 months after use of HFCWC compared with the 12 months before. ${ }^{28}$ Furthermore, none of the subjects experienced adverse events resulting from HFCWC use. Similarly, 15 children and young adults with familial dysautonomia experienced improved health outcomes in the year following HFCWC use compared with the year before, as reflected in fewer hospitalizations, episodes of pneumonia, days with antibiotics, courses of antibiotics, physician visits, and days of school absence. ${ }^{27}$ Additionally, resting oxyhemoglobin saturation increased from $94 \%$ (interquartile range $89-96 \%$ ) at baseline to $98 \%$ (interquartile range 98-98\%) at 12 months $(P=.004)$. Another observational study involving 22 neurologically impaired children also demonstrated a significant reduction in hospitalization rates from $45 \%$ before HFCWC use to 36 and $13 \%$ in the 1 and $2 \mathrm{y}$ after its use. ${ }^{26} \mathrm{~A}$ randomized, controlled trial involving 23 children with either cerebral palsy or NMD compared clinical outcomes, including duration of acute infections, adverse events, polysomnogram results, chest radiograph findings, and body mass index in a group who were treated with standard chest physiotherapy and another group who received HFCWC over 5 months. ${ }^{79}$ There were no thera-
Table 1. Typical Equipment Charges for Airway Clearance Therapies

\begin{tabular}{|c|c|c|}
\hline Equipment & Rental & Purchase \\
\hline MI-E & $\begin{array}{l}\$ 250 \text { to } \$ 350 / \mathrm{mo} \text {, capping } \\
\text { in } 10 \mathrm{mo}\end{array}$ & $\$ 4,000$ to $\$ 6,000$ \\
\hline HFCWC vest & & $\$ 10,000$ to $\$ 15,000$ \\
\hline IPV & $\begin{array}{l}\$ 300 \text { to } \$ 900 / \mathrm{mo} \text {, capping } \\
\text { in } 10-12 \mathrm{mo}\end{array}$ & \\
\hline $\begin{array}{l}\text { Portable suction } \\
\text { unit }\end{array}$ & $\begin{array}{l}\$ 30 \text { to } \$ 50 / \mathrm{mo} \text {, capping } \\
\text { in } 10 \mathrm{mo}\end{array}$ & \\
\hline Ambu bag & & $\$ 50$ \\
\hline \multicolumn{3}{|c|}{$\begin{array}{l}\text { Shown are typical charges for airway clearance equipment procured via a durable medical } \\
\text { equipment company. } \\
\text { MI-E = mechanical in-exsufflator } \\
\text { HFCWC = high-frequency chest-wall compression } \\
\text { IPV = intrapulmonary percussive ventilator }\end{array}$} \\
\hline
\end{tabular}

py-related adverse events. Although there was no difference between groups in oral or intravenous antibiotic use, there was a trend toward fewer hospitalizations for intravenous antibiotic therapy in the HFCWC group. That group also had higher maximum oxygen saturation, but there were no differences between groups in nocturnal saturations. There were also no differences either between groups or by the end of therapy in chest radiograph scores or body mass index. Notably, a post-study caregiver survey disclosed significantly better adherence to the prescribed thrice-daily therapy in the HFCWC group, with caregivers citing difficulty with the time required and positioning involved to provide chest physiotherapy.

Recently, Lechtzin et al ${ }^{80}$ compared health-care claims of patients with NMD from 2 large commercial insurance claim databases before and after use of HFCWC. Of the 426 subjects in the study, $43.9 \%$ were $0-18$ y old. For the group, total medical costs per member per month decreased $18.6 \%$ after HFCWC use $(P=.002)$, in-patient admission costs decreased by $41.7 \%(P=.001)$, and costs related to treatment of pneumonia decreased by $18.1 \%(P=.02)$. Although the data did not allow the authors to determine either frequency of HFCWC use or adherence to therapy, they speculated that the reductions in health-care utilization and claim costs were the result of a proactive airway clearance regimen that included HFCWC.

From the above data, it would seem reasonable to combine a mucus-mobilization device with mucus extraction, either by manually assisted cough or MI-E. It is often difficult, however, to get more than one piece of airway clearance equipment per patient approved by insurance companies, and the cost of the equipment can be greater than can be borne by a family (Table 1). Thus, additional data are critically needed to determine cost-effective strategies for airway clearance therapies for children with NMDs. 


\section{Respiratory Implications of Pediatric Neuromuscular Disease}

Table 2. Mucoactive Agents

\begin{tabular}{|c|c|c|}
\hline Effect & Action & Examples \\
\hline Expectorants & $\begin{array}{l}\text { Increase volume of mucus or increase mucus hydration; may } \\
\text { also induce cough }\end{array}$ & Guaifenesin, hypertonic saline \\
\hline Mucolytics & Lyse or decrease viscosity of mucus (dissociate disulfide bonds) & Dornase alfa \\
\hline Mucokinetics & Increase transportability of mucus with cough & $\beta_{2}$ agonists, surfactant \\
\hline Mucoregulators & Decrease mucus production & $\begin{array}{l}\text { Anticholinergics (ipratropium), macrolide } \\
\text { antibiotics, glucocorticoids }\end{array}$ \\
\hline
\end{tabular}

\section{Medications That Alter Mucociliary or Cough Clearance}

The characteristics of mucus and airway-lining fluid greatly affect how successfully either mucociliary clearance or cough clears the respiratory tract of secretions. Cough clearance is optimized when mucus has high viscosity and low tenacity, whereas mucus variables that favor effective mucociliary clearance are opposite to those that favor cough clearance. ${ }^{31}$ Thus, the more elastic the mucus, the better mucociliary clearance will be; the more viscous the mucus, the better cough clearance will be.

Agents that alter the properties of mucus have been divided into 4 categories (Table 2). Although several medications can alter the physical properties of mucus or the airway-lining fluid, all pharmacologic therapies aimed at enhancing airway clearance, including the use of bronchodilators, mucolytics like dornase alfa, and hyperosmolar agents like hypertonic saline, are considered off-label for children with NMD. ${ }^{81,82}$ Given the lack of clinical trials outside of those involving children with cystic fibrosis or bronchiolitis, such therapies are not recommended in most clinical practice guidelines for patients with NMD. ${ }^{13,81-83}$ Nevertheless, there are case reports on the use of dornase alfa for patients with neuromuscular weakness who developed atelectasis unresponsive to conventional therapies. ${ }^{29,84}$

Use of inhaled dornase alfa (DNase) has been shown to improve and slow the decline of lung function in children with cystic fibrosis. ${ }^{85,86}$ Patients with cystic fibrosis have purulent sputum with a large burden of necrotic neutrophils that release DNA into the sputum. DNase cleaves extracellular DNA and separates it from proteins. This reduces the concentration of highly polymerized DNA in sputum and allows endogenous proteolytic enzymes to lyse proteins, thereby decreasing the viscosity of sputum. ${ }^{31,87}$ In contrast, adults with non-cystic fibrosis bronchiectasis who were randomized to receive DNase in a large controlled trial had worse outcomes compared with those who received placebo. ${ }^{88}$ The reasons for the poorer results re- main unclear, but such findings highlight the point that just because a particular intervention works in one population with specific characteristics, such results may not be generalizable to all populations who may have different characteristics. There are several case series and small trials in which DNase has been used to treat infants with atelectasis. ${ }^{32}$ Although the only drug-related adverse events reported were transient episodes of hypoxemia after the drug was instilled through an endotracheal tube, the drug still must be used with caution in infants and children with neuromuscular weakness given the lack of data regarding its safety and effectiveness in that population.

In recent years, inhaled hypertonic saline has been used in older children with cystic fibrosis to help preserve lung function and reduce the frequency of pulmonary exacerbations ${ }^{89}$ and in infants with viral bronchiolitis to ameliorate lower airway obstruction and shorten the duration of hospitalization. ${ }^{90}$ There are no published case reports or series on the use of inhaled hypertonic saline in patients with NMD. Perhaps because of pediatricians' familiarity with using nebulized hypertonic saline in children with cystic fibrosis and in infants with bronchiolitis, anecdotally it has been increasingly prescribed during acute respiratory illnesses in patients with NMD.

Hypertonic saline probably has several different mechanisms of action. ${ }^{31,91}$ It is routinely used as an expectorant to aid patients in producing sputum for examination. ${ }^{92}$ This is probably the result of its osmotic effect on increasing the depth of the airway surface fluid layer, which also improves mucociliary clearance. ${ }^{93}$ It may also have mucolytic properties, by disrupting ionic bonds within the mucus gel, thereby reducing entanglements and cross-linking. ${ }^{94}$ Like DNase, hypertonic saline can also dissociate white cell DNA from mucoproteins, making the latter more amenable to digestion by proteolytic enzymes. ${ }^{91}$ Inhaled hypertonic saline may also have anti-inflammatory properties, including an increase in the levels of 2 compounds that protect against oxidant injury, glutathione and thiocyanate, in the airway surface liquid ${ }^{95}$ and possibly a reduction in interleukin-8, as demonstrated in bronchoalveolar lavage fluid of patients with cystic fibrosis. ${ }^{96}$ 
In contrast, inhaled hypertonic saline may have some deleterious effects. In a ferret model, exposure of airway epithelium to hypertonic saline resulted in a dose-dependent increase in mucus production. ${ }^{97}$ The authors cautioned that hyperosmolar solutions should be used with caution in patients with mucus hypersecretion and impaired mucus clearance. The use of inhaled hypertonic saline in adults with COPD before exercise 3 times/week resulted in less improvement in a 6-min walk test at the end of 8 weeks compared with a control group who received normal saline before exercising..$^{98}$ In addition, $12 \%$ of the treatment group experienced cough or bronchospasm as adverse events, whereas no adverse events were reported in the control group. A recent prospective study in intubated and mechanically ventilated children demonstrated no reduction in the duration of mechanical ventilation in a group who received 3\% inhaled hypertonic saline compared with those who received normal saline aerosols. ${ }^{99}$ Additionally, there was no improvement in lung mechanics or chest radiographic appearance following hypertonic saline administration, but 2 subjects had to be removed from the study because of hypoxemia that developed after hypertonic saline administration. Radioisotope studies of mucociliary clearance in healthy subjects treated with $3 \%$ inhaled hypertonic saline showed an initial acceleration of mucociliary clearance over the first $30 \mathrm{~min}$ after hypertonic saline inhalation but a slowing in mucociliary clearance at 3-6 h. ${ }^{100}$ The authors speculated that the reduction in clearance was the result of depletion of mucus in the central airways. Once again, these data collectively suggest that caution should be used when considering hypertonic saline therapy for patients with NMD. Studies are required to determine under what conditions inhaled hypertonic saline therapy is appropriate to use and will be most effective for children with NMD, as well as to identify the optimal dosing regimen.

Inhaled anticholinergic drugs like ipratropium bromide, tiotropium, atropine, and glycopyrrolate block mucus hypersecretion that is triggered by inflammatory or pharmacologic stimulation of M3 muscarinic receptors, but they do not reduce the normal production of mucus or increase its viscosity. ${ }^{101,102}$ In hypersecretory conditions like COPD, their use has been shown to decrease sputum volume. ${ }^{103}$ No such effect has been studied in patients with NMD. One of the adverse effects of these drugs is oral dryness, and they are frequently used enterally to treat sialorrhea. ${ }^{104,105}$ They are less effective anti-sialogogues when used by spraying the inhalational form of the drug into the mouth. ${ }^{106}$ Although excessive thickening of secretions is a common concern when using these medications enterally, it is not a frequently reported adverse effect. ${ }^{105,107}$

\section{Sleep Problems in Children With Neuromuscular Disorders}

As respiratory muscle weakness progresses, patients with NMD will not only have problems with atelectasis and recurrent pneumonias, but they will also develop problems with breathing during sleep. Under normal circumstances, sleep is associated with a reduction in minute ventilation and a decreased ventilatory response to both hypoxia and hypercapnia when compared with wakefulness. ${ }^{108-110}$ Additionally, tonic activity of pharyngeal dilator muscles, like the genioglossus, decreases. ${ }^{111}$ This causes an increase in extrathoracic ("upper-airway") resistance during nonREM sleep. ${ }^{112}$ In people with normal muscle function, there is augmented activity of intercostal muscles during non-REM sleep, resulting in a greater contribution of the rib cage to tidal volume. ${ }^{113}$ During REM sleep, atony of skeletal muscles excluding the diaphragm and extraocular muscles occurs, eliminating intercostal and accessory muscle contribution to inspiration and accentuating the dependence of gas exchange on diaphragm contraction. These changes contribute to a decrease in tidal volume and a slight increase in $\mathrm{P}_{\mathrm{aCO}_{2}}$ and also heighten extrathoracic airway resistance.

Neuromuscular weakness will magnify these alterations in breathing and thus lead to significant sleep-related hypercapnia and hypoxemia, often before daytime ventilatory impairment is recognized. ${ }^{1}$ During REM sleep, for instance, when breathing is primarily dependent on diaphragmatic contraction, those patients with diaphragm weakness, who at other times can maintain adequate gas exchange by using intercostal and accessory inspiratory muscles, will experience hypoventilation and gas exchange abnormalities. ${ }^{1,108,110,114}$ In addition to respiratory muscle weakness, other factors like kyphoscoliosis and obesity can exacerbate sleep-related hypoventilation. ${ }^{115-117}$ Furthermore, physical features of certain NMDs like flattening of the malar eminences, macroglossia, retrognathia, and bulbar involvement will predispose children to upperairway obstruction during sleep. Thus, it is easy to imagine that the array of sleep-disordered breathing problems that appear in any one patient will depend to some degree on the child's underlying neuromuscular condition, the degree of muscle weakness and distribution of involved muscles, the presence or absence of abnormal ventilatory control, and any other ancillary conditions.

\section{Epidemiology of Sleep-Disordered Breathing}

The constellation of problems that can occur during sleep in children with NMD include hypoventilation, hypoxemia, central and obstructive hypopneas and apneas, frequent arousals, sleep fragmentation, decreased sleep efficiency, and even seizures. ${ }^{1,110,118,119}$ Collectively, these 
symptoms comprise the term sleep-disordered breathing (SDB). The prevalence of SDB among patients with neuromuscular weakness has not been well studied, but one report found a frequency of SDB of $42 \%$ among 60 unselected adults and children with a variety of NMDs. ${ }^{117}$ That center, however, was at a high altitude $(1,500 \mathrm{~m})$, and only 10 of the subjects were children, so the generalizability of information to a pediatric population at sea level must be questioned. Nevertheless, studies involving smaller numbers of children with different NMDs estimate the prevalence of SDB to be as high as 70\%. ${ }^{109,120,121}$ In addition, one study in boys with DMD showed a prevalence of obstructive sleep apnea of $30 \%$, a rate 10 times higher than the prevalence reported in the general pediatric population. ${ }^{122}$ In the absence of large, longitudinal populationbased studies, the prevalence of SDB in children with NMD at different centers will vary, depending on the age at which the children are studied and the type of NMD being studied.

These 2 factors, patient age and natural history of the underlying disease, can also affect the type of respiratory disturbance identified. Suresh et al ${ }^{122}$ studied 34 subjects with DMD age 1-15 y referred to a sleep program for respiratory assessment. Ten had polysomnographic evidence of obstructive sleep apnea at 1-14 y of age (median $8 \mathrm{y})$. Over the 5-y observation period, 11 of the 34 subjects were found to have hypoventilation during sleep, and 9 began NIV at 11-15 y (median $13 \mathrm{y}$ ). The authors speculated that the observed bimodal distribution of SDB reflected age- and disease-related differences in muscle dysfunction: younger subjects with DMD who had better preservation of diaphragm function presented with obstructive sleep apnea. As respiratory muscle weakness ensued with increasing age, however, the boys might not have been able to generate enough negative intrathoracic pressure to develop upper-airway obstruction and thus presented more with sleep hypoventilation. ${ }^{123}$ This interpretation is consistent with the finding that the type of SDB encountered reflects the distribution of respiratory muscle involvement. ${ }^{110}$

As patients develop respiratory muscle weakness significant enough to affect gas exchange, they will compensate for hypoventilation with an arousal response. The arousal limits the extent of hypoxemia and hypercapnia by changing the sleep state, recruiting respiratory and upperairway muscular activity, and depth of ventilation. ${ }^{1} \mathrm{Al}-$ though arousals constitute a protective mechanism against hypoventilation, they cause sleep disruption, poor sleep quality, sleep fragmentation, and reduced sleep time. Sequelae of frequent arousals include daytime somnolence and fatigue as well as poor school performance. ${ }^{124}$ With persistent hypoventilation and its accompanying sleep fragmentation and deprivation, ventilatory chemoreceptor responses become blunted, resulting in fewer arousals, longer periods of REM sleep, and longer periods of hypoventilation with hypoxemia. ${ }^{1,110}$ Renal compensation for persistent hypercapnia further dampens chemoreceptor sensitivity, causing even more severe hypoventilation and a blunted respiratory drive. Hypercapnia, initially confined to REM sleep, extends into non-REM sleep and eventually results in diurnal hypercapnia. ${ }^{125-127}$ Such a progression is life-threatening: mean survival in patients with DMD once diurnal hypercapnia developed was 9.7 months in the absence of ventilatory assistance. ${ }^{128}$

This sequence of events leading to progressive hypoventilation is common among patients with NMD. There are some conditions, however, where alterations in control of breathing are a part of the primary condition and not the result of progressive muscle weakness. Children with myelomeningocele and Chiari malformation can demonstrate periodic breathing, hypoxemia, and abnormal responsiveness to $\mathrm{CO}_{2}$ challenge immediately after birth. ${ }^{129} \mathrm{~A}$ primary disorder in ventilatory control has also been reported in children and adults with myotonic dystrophy, perhaps related to neuronal loss and gliosis in the reticular activating system and brainstem. ${ }^{130,131}$ Similarly, patients who experienced bulbar poliomyelitis can demonstrate SDB and abnormal responses to hypoxic and hypercapnic challenges years after the primary infection. ${ }^{132}$

\section{Evaluation of Sleep-Disordered Breathing}

Children with NMD who have SDB can have subtle symptoms that may be difficult to distinguish as arising from something other than the underlying neuromuscular disease. For instance, children may complain of fatigue or excessive daytime sleepiness. Fatigue can result from progression of skeletal muscle weakness and not be at all associated with disorders of breathing. Excessive daytime somnolence is a hallmark of myotonic dystrophy and is not directly related to the presence of SDB. ${ }^{130}$ Symptoms and signs frequently associated with SDB are listed in Table 3.1,108,110,114,118,121,125 These often appear insidiously and should be actively sought by the clinician. Although they offer clues to the presence of SDB, they are not specific. Furthermore, there is poor correlation between results of symptom questionnaires in patients with NMD and polysomnographic findings of SDB. ${ }^{108,117,119,122,133-135}$

Because symptoms and signs alone are unreliable in detecting SDB and polysomnography is both cumbersome and often limited in availability, investigators have sought various daytime tests that might predict the presence of SDB. There are, however, no simple relationships between awake measurements of pulmonary function or respiratory muscle strength and SDB. ${ }^{110}$ For instance, a fall in FVC $\geq 25 \%$ associated with a change from seated (upright) to supine position is a good indicator of diaphragmatic weakness. ${ }^{136}$ Although diaphragm weakness is a risk factor for 


\section{Respiratory Implications of Pediatric Neuromuscular Disease}

Table 3. Signs and Symptoms Suggestive of Sleep-Disordered Breathing

\begin{tabular}{|c|c|c|}
\hline Symptoms & Signs & Laboratory Findings \\
\hline $\begin{array}{l}\text { Morning lethargy, daytime hypersomnolence } \\
\text { Fatigue } \\
\text { Insomnia, poor sleep quality } \\
\text { Morning headache } \\
\text { Orthopnea, dyspnea } \\
\text { Anorexia, poor growth, failure to thrive } \\
\text { Snoring } \\
\text { Restless legs } \\
\text { Poor school performance, attention deficit } \\
\text { Mood changes } \\
\text { Night sweats } \\
\text { Hypoxic seizures }\end{array}$ & $\begin{array}{l}\text { Adenotonsillar hypertrophy, mouth breathing, } \\
\text { hyponasal speech } \\
\text { Macroglossia, facial and lingual myopathy } \\
\text { Cor pulmonale, heart failure } \\
\text { Hypertension } \\
\text { Digital clubbing }\end{array}$ & $\begin{array}{l}\text { Polycythemia } \\
\text { Daytime } \mathrm{P}_{\mathrm{aCO}}>45 \mathrm{~mm} \mathrm{Hg} \text {; base } \\
\quad \text { excess }>4 \mathrm{mmol} / \mathrm{L}\end{array}$ \\
\hline
\end{tabular}

hypoventilation during REM sleep, no correlation between a fall in the supine FVC and the presence of SDB could be found in 21 subjects with DMD. ${ }^{120}$ Similarly, several investigators have shown little or no correlation of pulmonary function studies like the $\mathrm{FVC}$ or $\mathrm{FEV}_{1}$ and SDB events. ${ }^{119,120,122,137}$

Others, however, have shown statistically significant relationships between pulmonary function tests and nocturnal breathing events. ${ }^{121,125,135,138}$ Katz et al ${ }^{135}$ evaluated 46 children with progressive NMD and found a prevalence of nocturnal hypoventilation of $15 \%$, although the group was not selected for concerns about SDB. The investigators found a significant relationship between nocturnal hypoventilation and an FVC $<70 \%$ of predicted (sensitivity 71.4, specificity 64.1) or $\mathrm{FEV}_{1}<65 \%$ of predicted (sensitivity 71.4, specificity 79.5). The authors noted that their cutoff values in otherwise asymptomatic children were higher than those reported in adults who were symptomatic at the time of testing, many of whom had diurnal hypercapnia. ${ }^{138}$ Mellies et al ${ }^{121}$ evaluated 49 children 5-18 y old with a variety of NMDs for SDB. Lung functions, including an inspiratory vital capacity (IVC), FVC, FEV ${ }_{1}$, and maximum inspiratory pressure were measured and compared with polysomnogram results. The investigators found significant correlations between both the IVC and maximum inspiratory pressure and SDB events. Furthermore, those children who had an IVC $<60 \%$ of predicted were noted to have the onset of SDB without hypercapnia (sensitivity $97 \%$, specificity $87 \%$ ); those with an IVC $<40 \%$ of predicted were likely to have hypercapnic hypoventilation (sensitivity 96\%, specificity $88 \%$ ). The same investigators studied a group of 42 children and adults $14-63 \mathrm{y}$ old with primary myopathies and found similar correlations between values of percent-of-predicted IVC and SDB. ${ }^{125}$ It may be that because the IVC primarily reflects inspiratory muscle function, whereas the FVC is affected by both inspiratory and expiratory muscle function, the IVC will prove to be a better predictor of SDB resulting from diaphragm dysfunction. Similar comparisons using the IVC will need to be made in other centers to confirm its utility in predicting nocturnal breathing events.

With these relationships in mind, a panel of 10 experts developed consensus recommendations for the respiratory assessment of patients with DMD. ${ }^{139}$ The experts strongly recommended assessment of gas exchange during sleep for any patients with signs or symptoms of hypoventilation. They noted that the assessment of gas exchange during sleep should be strongly considered in any patients with a baseline FVC $<40 \%$ of predicted, an awake baseline end-tidal partial pressure of carbon dioxide $\left(\mathrm{P}_{\mathrm{ETCO}_{2}}\right)$ $>45 \mathrm{~mm} \mathrm{Hg}$, and/or an awake baseline $\mathrm{S}_{\mathrm{pO}_{2}}<95 \%$. In teenagers and older patients, similar assessments should be made if the FVC falls below 1.25 L. ${ }^{139}$

As noted, history and physical examination findings are neither sensitive nor specific in identifying patients with SDB. Furthermore, daytime tests of lung function do not reliably identify patients with SDB in the absence of diurnal hypercapnia. Thus, screening tests are required to detect SDB in children with neuromuscular weakness before the advanced finding of daytime hypercapnia develops. Guidelines for the care of children with NMDs recommend at least annual testing for patients who become non-ambulant because of weakness or for those who never walked. ${ }^{13,14,140}$ Other statements acknowledge the need for testing but do not specify intervals. ${ }^{18,141}$ There are, in fact, no studies that evaluate the required frequency of testing for SDB in patients with NMD. There may be situations in which more frequent monitoring is required (eg, if a child's course of weakness becomes rapidly progressive).

There are several different tests that are used to detect SDB. They vary in complexity and availability. The accepted standard for determining the presence of SDB in patients with neuromuscular weakness is the polysomnogram. ${ }^{13,14,140}$ The polysomnogram provides monitoring of cardiorespiratory function including heart rate, breathing frequency, abdominal and chest-wall movements, nasal air 
flow, oximetry, limb movement, sleep position, and video monitoring during sleep, as well as simultaneous monitoring of sleep with continuous electroencephalogram, electromyogram, and electrooculogram. For patients with neuromuscular weakness, it is also critical that exhaled and/or transcutaneous $\mathrm{CO}_{2}$ is monitored as part of the study to detect nocturnal hypoventilation. This constellation of monitoring not only provides information about gas exchange during sleep, but also yields important information about sleep quality. Polysomnography, however, is cumbersome, intrusive, labor-intensive, and expensive. The act of monitoring itself can disturb a child's sleep and yield inaccurate results if the child does not achieve the usual amount of REM sleep. Its availability for children varies widely, and its scarcity has been associated with differences in practice patterns of how children with NMD are monitored for SDB. ${ }^{142}$

With the recognition that polysomnogram monitoring in a pediatric sleep laboratory may not be widely available, other screening tests have been used to detect nocturnal hypoventilation or other forms of SDB. Home pulse oximetry studies with a simultaneous pulse waveform are considered a reasonable method to screen for SDB. ${ }^{13,14,140}$ Oximetry studies, however, cannot differentiate between hypoxemia secondary to obstructive apneas and hypoventilation. Since appropriate therapeutic interventions require such a determination, this is a significant shortcoming of the test. One can infer that hypoxemia is the result of obstructive sleep apnea when desaturations occur in clusters of a saw-toothed pattern cyclically during periods of REM sleep, as opposed to the prolonged and sustained desaturations noted with nocturnal hypoventilation. ${ }^{14,118}$ Oximetry studies can be hampered by movement artifact, long signal averaging, and poor signal detection. ${ }^{118}$ Arousals that help to avoid episodes of hypoxemia also will not be detected. Another limitation of pulse oximetry monitoring was highlighted by investigators who performed simultaneous overnight transcutaneous $\mathrm{CO}_{2}$ and oximetry recordings in children supported by NIV. ${ }^{143}$ They showed that significant episodes of hypoventilation could go undetected, when the $\mathrm{S}_{\mathrm{pO}_{2}}$ remained normal despite an elevation of transcutaneous $\mathrm{CO}_{2}$ to $\geq 50 \mathrm{~mm} \mathrm{Hg}$. Nevertheless, the British Thoracic Society recognizes overnight pulse oximetry as an acceptable method of screening for nocturnal hypoventilation in asymptomatic children with NMD if polysomnography or simultaneous capnography monitoring is not available. ${ }^{14}$ The guidelines caution, however, that oximetry monitoring alone is not an adequate screening tool for symptomatic children.

The addition of capnography (either transcutaneous or end-tidal) to oximetry monitoring improves detection of nocturnal hypoventilation, although this combination has not been methodically studied. Such episodes would appear as prolonged periods of hypoxemia (low $\mathrm{S}_{\mathrm{pO}_{2}}$ ) with simultaneous hypercapnia (elevated transcutaneous $\mathrm{CO}_{2}$ or $\mathrm{P}_{\mathrm{ETCO}_{2}}$ ). Most of the current guidelines for evaluation of children with various NMDs recommend a study with the combination of oximetry and capnography or transcutaneous $\mathrm{CO}_{2}$ monitoring as a screening test if polysomnography is not available and an overnight oximetry study if neither polysomnography nor oximetry with capnography studies are available. ${ }^{13,14,18,140}$ Attempts to perform overnight studies at home in adults and children with NMD are in the early stage of investigation but offer some promise. ${ }^{144,145}$

\section{Ventilatory Support for Children With NMD}

\section{The Impact of Ventilatory Support in NMDs}

In general, the goals of chronic mechanical ventilatory support in children are to prolong survival, relieve dyspnea, normalize gas exchange, correct SDB and abnormal sleep architecture, prevent or reverse cor pulmonale, improve daytime function, and promote and sustain growth and development. For patients with progressive NMDs, the addition of mechanical ventilation at night or continuously has changed the natural history of their diseases. One of the first reports of improved survival resulting from ventilatory support in young men with DMD compared 5 subjects who used NIV at least $7 \mathrm{~h} /$ night with 5 subjects who refused NIV. ${ }^{128}$ Four of those who refused NIV died $9.7 \pm 5.8$ months from the onset of daytime hypercapnia, whereas all of those who used NIV survived. Among 23 young men with DMD who had diurnal hypercapnia and evidence of severe nocturnal hypoventilation, institution of NIV not only improved survival, but also resulted in normalization of daytime $\mathrm{P}_{\mathrm{aO}_{2}}$ and $\mathrm{P}_{\mathrm{aCO}_{2}}{ }^{126} \mathrm{In}$ a retrospective review, Passamano et al ${ }^{146}$ divided 516 subjects with DMD into groups based on epochs of birth: 1961-1970, 1971-1980, and 1981-1990. They found improved survival related to the institution of mechanical ventilation at 20 and $25 \mathrm{y}$ with each increasing decade of birth (Fig. 2). The overall mean age of death for those subjects who did not receive mechanical ventilatory support was 17.7 y (range 11.6-27.5 y), but it was significantly higher (mean 27.9 y, range 23-38.6 y) in those who used mechanical ventilation.

The effect of nocturnal NIV on diurnal gas exchange has been confirmed elsewhere. In a prospective trial of NIV in 30 children from 6 to $19 \mathrm{y}$ of age with a variety of NMDs, Mellies et al ${ }^{147}$ demonstrated normalization of nocturnal gas exchange in all subjects and normal diurnal gas exchange in those who had demonstrated diurnal hypercapnia. The effect was sustained over $25.3 \pm 12.7$ months of observation. Furthermore, in 10 of the subjects who agreed to forego NIV for 3 consecutive nights, measurements of nocturnal and diurnal gas exchange quickly de- 


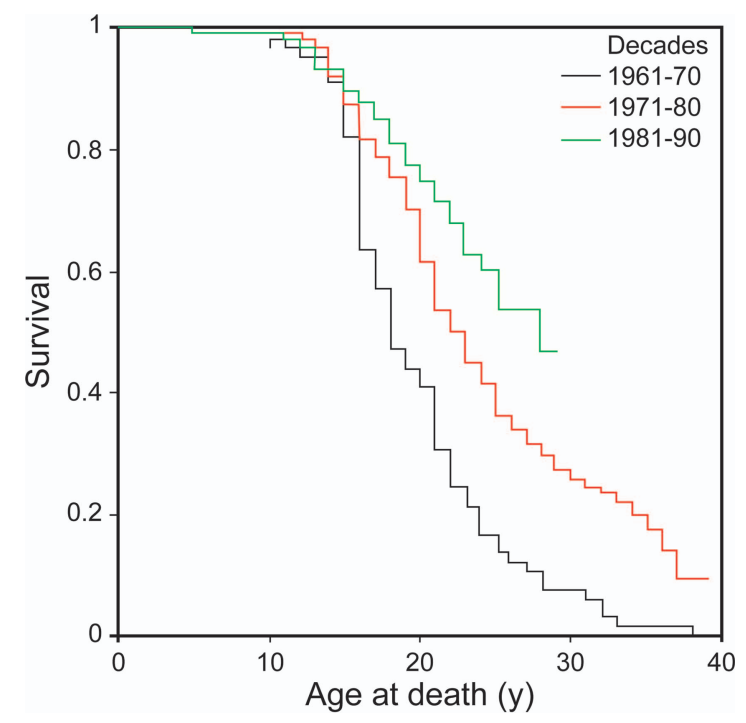

Fig. 2. Kaplan-Meier curves demonstrating the improved survival of men with DMD by decade of birth from the 1960s to the 1990s. Innovations in treatment that included use of NIV, ACE inhibitors for cardiomyopathy, and deflazacort to preserve muscle function were introduced in this center at the beginning of the 1990s. From Reference 147, with permission.

teriorated but were then promptly restored with the reinstitution of NIV.

There have been other salutary outcomes attributed to the introduction of NIV for patients with NMD. One retrospective review involving 15 children between 3.4 and $17.8 \mathrm{y}$ of age with a variety of NMDs also compared outcomes in the year before and after NIV initiation. ${ }^{148}$ There was a significant reduction in number of days spent in the hospital and in length of stay in the pediatric ICU in the year following commencement of NIV versus the prior year. Two of the subjects also reported improvement in school performance. Another retrospective review of 14 children with NMD between 1.5 and 16 y of age who were treated with NIV reported a $73 \%$ reduction in hospitalizations in the year after institution of NIV support versus the year before it was begun. ${ }^{149}$ There was also a trend toward a reduction in pediatric ICU days from 10.2 to $2.3 \mathrm{~d}(P=.06)$ and a significant reduction in health-care costs per patient from $\$ 55,129$ in the year before NIV use to $\$ 14,914$ in the year after $(P=.003)$. In addition, a survey of the subjects and families showed no adverse effects on quality of life related to the introduction of NIV in this small cohort. In addition to improving gas exchange and sleep quality, NIV can also alter chest-wall growth. In children with SMA, the use of NIV with inspiratory pressures $>14 \mathrm{~cm} \mathrm{H}_{2} \mathrm{O}$ has been shown to prevent or reverse the development of pectus excavatum. ${ }^{150,151}$ It is not known, however, whether such alterations in chest-wall shape also promote lung growth by enhancing alveolarization. ${ }^{150}$

\section{When to Institute Ventilatory Support}

Once sleep-related hypoxemia or hypoventilation is recognized in patients with NMD, recommendations are to offer patients ventilatory support, typically in the form of NIV. ${ }^{13,14,139}$ Aside from the presence of hypoxemia or hypercapnia while asleep or awake, however, there is not consensus on when exactly to begin NIV in different diseases. Some recommend that markers like acute respiratory failure, failure to thrive, recurrent pneumonia, or symptomatic diurnal hypercapnia be used as triggers to institute long-term NIV. ${ }^{152}$ An apnea-hypopnea index $>10 / \mathrm{h}$ or $\geq 4$ episodes of $\mathrm{S}_{\mathrm{pO}_{2}}<92 \%$ or drops in $\mathrm{S}_{\mathrm{pO}_{2}} \geq 4 \% / \mathrm{h}$ of sleep on polysomnography have also been recommended as indications to begin NIV. ${ }^{139}$ One center in Sweden surveyed their patients to determine the primary motive for commencing NIV. ${ }^{153}$ Of 352 adults and children with a variety of NMDs, mechanical ventilation was begun electively in 268 (76\%) and during an acute illness in the remainder. This cohort represented mostly adults, and no patient $<5$ y old was included. In those who began NIV electively, daytime sleepiness was the most common symptom, but in the subgroup of children with SMA, an insufficient cough was the most common reason to begin NIV. Hypercapnia occurred more frequently than hypoxemia in those who began NIV electively; notably, however, hypercapnia did not occur more frequently in those who complained of daytime sleepiness or headache versus those who did not.

French investigators hypothesized that the introduction of NIV before boys with DMD became symptomatic would delay the loss of lung function. In a multi-center national trial, they randomized those with normal daytime gas exchange along with an FVC between 20 and 50\% predicted to begin nocturnal NIV or to continue standard therapy. ${ }^{154}$ Enrollment in the study was curtailed, however, because investigators noted a decreased survival rate among the ventilated patients compared with controls. They speculated that NIV caused subjects to have a false sense of security, and therefore they practiced less careful monitoring. There was little description of the types of interventions used for airway clearance, however, and 7 of 10 deaths resulted from retained secretions and respiratory infection. Further, within the NIV group, 15 (43\%) were inadequately supported by nocturnal mechanical ventilation. There was also a greater proportion of subjects with cardiomyopathy in the NIV group. For all these reasons, the dire warning of the authors to avoid NIV use until mechanical ventilation becomes imperative must be interpreted with caution.

Recognizing that waiting until daytime hypercapnia develops before starting NIV might subject patients with NMD to uncontrolled respiratory decompensation, Ward et al ${ }^{133}$ conducted a randomized trial of NIV use in subjects with NMD or restrictive chest-wall disease who had 
nocturnal hypoventilation but normal daytime gas exchange. Twenty-six subjects were randomized to receive nocturnal NIV $(n=14)$ or to be treated conservatively without NIV $(n=12)$, but those in the control group were started on NIV if they developed daytime hypercapnia, worsening symptoms of nocturnal ventilation, recurrent chest infections, failure to thrive, or acute ventilatory decompensation. Those in the NIV group demonstrated improvement in gas exchange at 24 months of follow-up and better quality of life scores at 18 months than the controls. Of the 10 control group patients who were followed for the entire 24-month period, 7 had begun NIV by 12 months, and all but one met criteria to use NIV by 24 months of observation. The authors noted, therefore, that once a patient with NMD demonstrates nocturnal hypoventilation, diurnal respiratory failure is likely within 12-24 months. These data provide some framework for caregivers to use in discussing the role of NIV once patients have been diagnosed with nocturnal hypoventilation.

Once ventilatory support is commenced, the goal of support is to restore normal blood gas values. Since patients with NMD do not have intrinsic lung disease, targets of support should include a normal awake $\mathrm{P}_{\text {ETCO }_{2}}(35-45 \mathrm{~mm} \mathrm{Hg})$ and an $\mathrm{S}_{\mathrm{pO}_{2}}>95 \%$ while the patient breathes room air. In fact, a decrease in oxyhemoglobin saturation in patients already receiving NIV support is an early sign of lower-respiratory tract dysfunction like atelectasis or pneumonia and is a signal to increase airway clearance measures. ${ }^{155}$

Although it is clear that NIV improves sleep quality and survival in patients with NMD, NIV use in the treatment of acute respiratory failure or identification of SDB does not always trigger a discussion by health-care providers with patients about starting long-term NIV. In one center where 50 of 73 patients $(69 \%)$ commenced NIV non-electively because of respiratory failure caused by pneumonia, the authors noted 191 missed prior opportunities to discuss beginning NIV with their patients. ${ }^{156}$ Having a well-defined educational plan for patients and families that takes into account the stage of the patient's respiratory dysfunction, as detailed in the American Thoracic Society guidelines, ${ }^{13}$ might help to facilitate such discussions.

\section{Noninvasive Ventilation Versus Ventilation via Tracheostomy}

Patients with progressive NMDs who initially present with diurnal hypercapnia often experience improvement in daytime gas exchange as a result of nocturnal ventilatory assistance but eventually again develop daytime hypercapnia as respiratory muscles continue to weaken. ${ }^{127}$ Once that occurs, patients require extended periods of ventilatory support to normalize gas exchange. This can be ac-

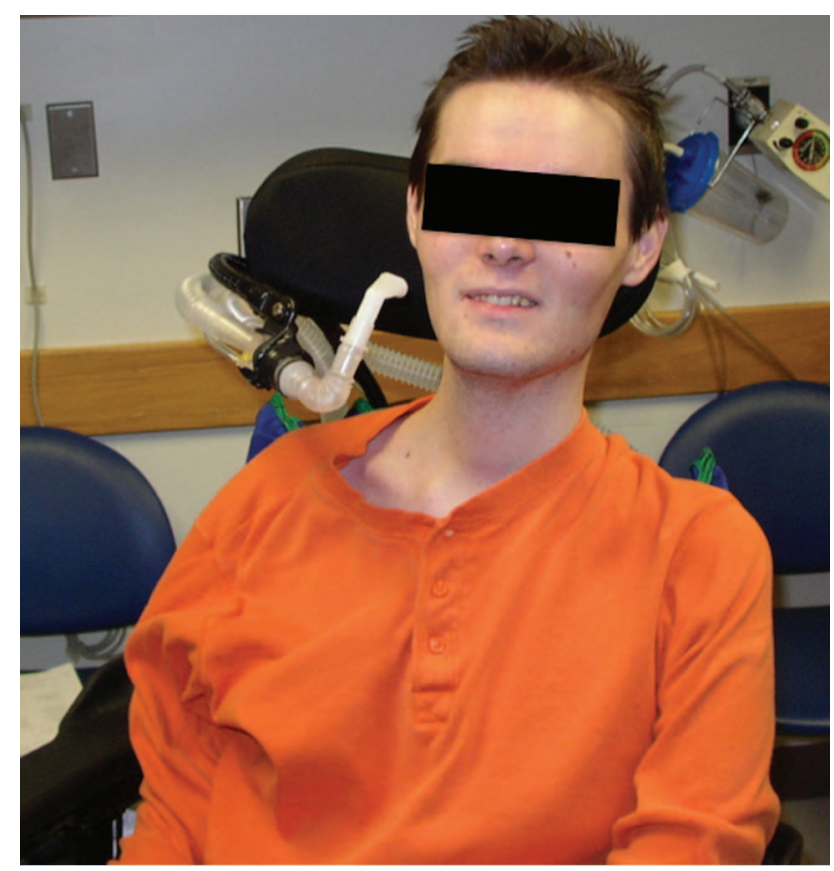

Fig. 3. Use of mouthpiece (sip) ventilation in a young man with Duchenne muscular dystrophy. The angled mouthpiece is positioned within easy reach of the patient's mouth for access to assisted ventilation as needed. The ventilator is mounted on the back of the patient's wheelchair.

complished with noninvasive methods or with invasive ventilation via tracheostomy. Although methods of NIV include negative-pressure body ventilators (tank ventilator or iron lung, cuirass, or chest shell) and in older children and adolescents positive-pressure body ventilators (pneumobelt), by far the most common method of providing NIV is via positive pressure through a nasal, oronasal, or oral interface.

If a patient requires continuous mechanical ventilatory support, a noninvasive approach is still feasible. Older patients can receive daytime ventilatory support through a mouthpiece placed close to the patient's mouth, which can be accessed whenever he or she wishes ${ }^{157}$ (Fig. 3). Several home-care ventilators can be adapted to provide this method of NIV, and some ventilators include settings for mouthpiece ventilation. ${ }^{158,159}$ If the child is too young to understand how to use this sip ventilation or the buccal musculature is too weak to prevent leakage of air from the mouth, a nasal interface can still be used for most or all of the day (Fig. 4). Although there have been no randomized controlled trials comparing continuous NIV with invasive ventilation via tracheostomy, observational studies in which other aspects of care are similar demonstrate prolonged survival with either technique. ${ }^{160,161}$

Advantages of NIV over invasive ventilation via tracheostomy include less risk of laryngeal or tracheal injury, fewer respiratory illnesses, less problem with mucus hypersecre- 


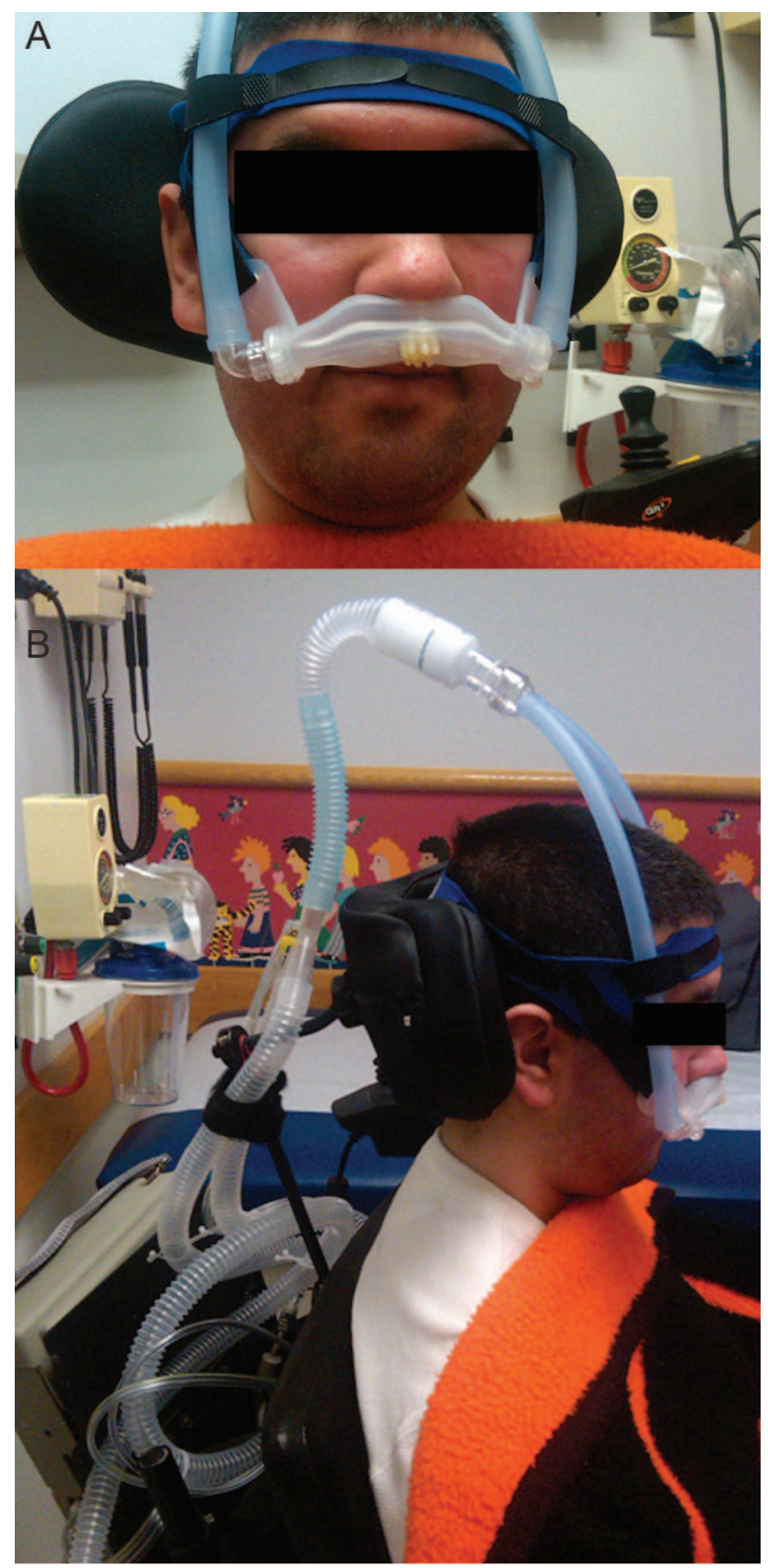

Fig. 4. Use of continuous nasal ventilation in a young man with Duchenne muscular dystrophy and excessively weak buccal musculature. A: Note the alteration of the nasal interface, transforming it from a vented to a non-vented interface for use with a dual-limb ventilator circuit. B: The circuit is attached to a portable ventilator mounted on the back of the wheelchair to facilitate mobility and extended duration of support away from an electrical power source.

tion, and less complexity of care. ${ }^{157,160,162}$ NIV also preserves oropharyngeal function for speaking, swallowing, and coughing, ${ }^{162}$ although one group found that weight loss and feeding problems occurred more frequently in their NIV group than in those supported by invasive ventilation via tracheostomy. ${ }^{160}$
Use of NIV is also associated with shorter length of hospitalization when it is initiated, and one study demonstrated that children and adults could begin NIV as out-patients with the same rate of success as those started as in-patients. ${ }^{163} \mathrm{In}$ adults, NIV was shown to be significantly less expensive than invasive ventilation via tracheostomy and more often associated with an ability of subjects to be cared for at home, ${ }^{164}$ whereas those adults supported by invasive ventilation via tracheostomy are more likely to be institutionalized. ${ }^{160,164}$ Complications of NIV include inadequate triggering and cycling of the device in small children; leaks through the mouth or around the mask that impair adequate ventilation or irritate the eyes; intestinal bloating and aerophagia; dryness of the nose, mouth, and airways; facial, sinus, ear, or nasal discomfort from the interface; skin breakdown or irritation; and orthodontic problems. ${ }^{165,166}$ Young children can also develop flattening of the midface and maxillary retrusion following longterm use of nasal interfaces for NIV 167-169 (Fig. 5). The use of custom-made nasal interfaces, which are more readily available in Europe than in the United States, can circumvent many of the complications related to the interface. ${ }^{167,170}$

Contraindictions for NIV include severe hypoxemia, moderate to severe bulbar weakness associated with aspiration, an inability to clear the airway of secretions despite augmented cough techniques, failure to thrive or recurrent infections despite the use of NIV, an inability to tolerate noninvasive interfaces, patient preference, and lack of health-care provider familiarity with continuous NIV. ${ }^{157,162,171}$ In those situations, tracheostomy should be considered.

\section{Summary}

There is a typical progression of respiratory complications in patients with NMDs that begins with respiratory and bulbar muscle weakness and proceeds to sleep-disordered breathing with the eventual development of nocturnal and then diurnal hypercapnia. These predictable problems form the framework for determining which assessments and interventions are necessary. Early interventions are aimed at overcoming impaired airway clearance. Many of the indicators that are used to detect respiratory impairment in patients with NMD, however, have been established for adult patients and do not necessarily pertain to children. The role of combinations of airway clearance devices and their potential to improve quality of life and reduce hospitalizations and frequency of lowerrespiratory tract infections should be determined, and best settings for those devices should be established for children. Other therapies, like the use of various medications that alter the properties of mucus, require critical scrutiny. Evidence of sleep-disordered breathing and nocturnal hypoventilation must be actively sought to prevent sig- 


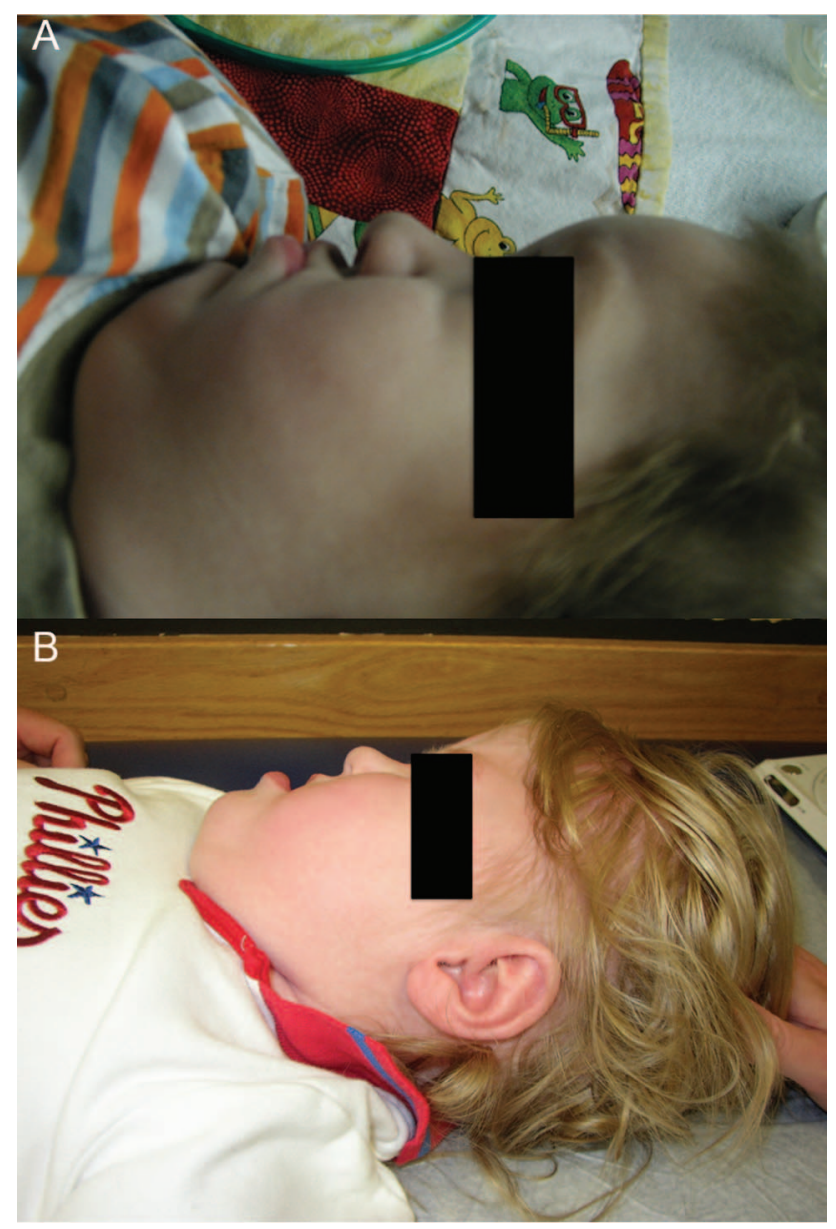

Fig. 5. Alteration in the shape of the face of a boy with myotubular myopathy $(A)$ and a girl with congenital myasthenia gravis (B). Note the flattening of the malar eminences and resulting concave profile of the face resulting from prolonged use of NIV via nasal mask.

nificant morbidity. Those children with progressive NMDs are at risk to develop diurnal ventilatory insufficiency, even after nocturnal ventilatory support has been instituted. Pediatric-specific evaluation tools to detect children at risk for SDB are required to improve care, and the necessary frequency of testing for SDB needs to be determined. Because application of airway clearance techniques and assisted ventilation has contributed to prolonged survival for many children with NMD, the development of coordinated programs to transition these patients to adult care is imperative to enhance their quality of life.

\section{REFERENCES}

1. Perrin C, Unterborn JN, Ambrosio CD, Hill NS. Pulmonary complications of chronic neuromuscular diseases and their management. Muscle Nerve 2004;29(1):5-27.
2. Leith DE. Cough. In: Brain JD, Proctor D, Reid L, editors. Respiratory defense mechanisms, Part II. New York: Marcel Dekker; 1977:545-592.

3. Roussos C, Macklem PT. The respiratory muscles. N Engl J Med 1982;307(13):786-797.

4. Fink JB. Forced expiratory technique, directed cough, and autogenic drainage. Respir Care 2007;52(9):1210-1221; discussion 12211213.

5. Warwick WJ. Mechanisms of mucous transport. Eur J Respir Dis Suppl 1983;127:162-167.

6. Leith DE. The development of cough. Am Rev Respir Dis 1985; 131(5):S39-S42.

7. Bach JR, Saporito LR. Criteria for extubation and tracheostomy tube removal for patients with ventilatory failure: a different approach to weaning. Chest 1996;110(6):1566-1571.

8. Szeinberg A, Tabachnik E, Rashed N, McLaughlin FJ, England S, Bryan CA, Levison H. Cough capacity in patients with muscular dystrophy. Chest 1988;94(6):1232-1235.

9. Mier-Jedrzejowicz A, Brophy C, Green M. Respiratory muscle weakness during upper respiratory tract infections. Am Rev Respir Dis 1988;138(1):5-7.

10. Poponick JM, Jacobs I, Supinski G, DiMarco AF. Effect of upper respiratory tract infection in patients with neuromuscular disease. Am J Respir Crit Care Med 1997;156(2 Pt 1):659-664.

11. Tzeng AC, Bach JR. Prevention of pulmonary morbidity for patients with neuromuscular disease. Chest 2000;118(5):1390-1396.

12. Bach JR, Ishikawa Y, Kim H. Prevention of pulmonary morbidity for patients with Duchenne muscular dystrophy. Chest 1997;112(4): 1024-1028.

13. Finder JD, Birnkrant D, Carl J, Farber HJ, Gozal D, Iannaccone ST, et al. Respiratory care of the patient with Duchenne muscular dystrophy: ATS consensus statement. Am J Respir Crit Care Med 2004;170(4):456-465.

14. Hull J, Aniapravan R, Chan E, Chatwin M, Forton J, Gallagher J, et al. British Thoracic Society guideline for respiratory management of children with neuromuscular weakness. Thorax 2012; 67(Suppl 1):i1-i40.

15. Toussaint M, Boitano LJ, Gathot V, Steens M, Soudon P. Limits of effective cough-augmentation techniques in patients with neuromuscular disease. Respir Care 2009;54(3):359-366.

16. Croteau JR, Cook CD. Volume-pressure and length-tension measurements in human tracheal and bronchial segments. J Appl Physiol 1961;16:170-172.

17. Bianchi C, Baiardi P. Cough peak flows: standard values for children and adolescents. Am J Phys Med Rehabil 2008;87(6):461-467.

18. Wang CH, Finkel RS, Bertini ES, Schroth M, Simonds A, Wong B, et al. Consensus statement for standard of care in spinal muscular atrophy. J Child Neurol 2007;22(8):1027-1049.

19. Dail CW. "Glossopharyngeal breathing" by paralyzed patients; a preliminary report. Calif Med 1951;75(3):217-218.

20. Braun SR, Giovannoni R, O'Connor M. Improving the cough in patients with spinal cord injury. Am J Phys Med 1984;63(1):1-10.

21. Kirby NA, Barnerias MJ, Siebens AA. An evaluation of assisted cough in quadriparetic patients. Arch Phys Med Rehabil 1966; 47(11):705-710.

22. Bach JR. Mechanical insufflation-exsufflation: comparison of peak expiratory flows with manually assisted and unassisted coughing techniques. Chest 1993;104(5):1553-1562.

23. Birnkrant DJ, Pope JF, Lewarski J, Stegmaier J, Besunder JB. Persistent pulmonary consolidation treated with intrapulmonary percussive ventilation: a preliminary report. Pediatr Pulmonol 1996; 21(4):246-249.

24. Reardon CC, Christiansen D, Barnett ED, Cabral HJ. Intrapulmonary percussive ventilation vs incentive spirometry for children 


\section{Respiratory Implications of Pediatric Neuromuscular Disease}

with neuromuscular disease. Arch Pediatr Adolesc Med 2005;159(6): 526-531.

25. Toussaint M, De Win H, Steens M, Soudon P. Effect of intrapulmonary percussive ventilation on mucus clearance in Duchenne muscular dystrophy patients: a preliminary report. Respir Care 2003; 48(10):940-947.

26. Fitzgerald K, Dugre J, Pagala S, Homel P, Marcus M, Kazachkov M. High-frequency chest wall compression therapy in neurologically impaired children. Respir Care 2014;59(1):107-112.

27. Giarraffa P, Berger KI, Chaikin AA, Axelrod FB, Davey C, Becker B. Assessing efficacy of high-frequency chest wall oscillation in patients with familial dysautonomia. Chest 2005;128(5):3377-3381.

28. Plioplys AV, Lewis S, Kasnicka I. Pulmonary vest therapy in pediatric long-term care. J Am Med Dir Assoc 2002;3(5):318-321.

29. Hendriks T, de Hoog M, Lequin MH, Devos AS, Merkus PJ. DNase and atelectasis in non-cystic fibrosis pediatric patients. Crit Care 2005;9(4):R351-R356.

30. McLaughlin AM, McGrath E, Barry R, Egan JJ, Gallagher CG. Treatment of lobar atelectasis with bronchoscopically administered recombinant human deoxyribonuclease in cystic fibrosis? Clin Respir J 2008;2(2):123-126.

31. Rogers DF. Mucoactive agents for airway mucus hypersecretory diseases. Respir Care 2007;52(9):1176-1193; discussion 1193-1177.

32. Thornby KA, Johnson A, Axtell S. Dornase alfa for non-cystic fibrosis pediatric pulmonary atelectasis. Ann Pharmacother 2014; 48(8):1040-1049.

33. Hess DR. The evidence for secretion clearance techniques. Respir Care 2001;46(11):1276-1293.

34. Bach JR, Smith WH, Michaels J, Saporito L, Alba AS, Dayal R, Pan J. Airway secretion clearance by mechanical exsufflation for post-poliomyelitis ventilator-assisted individuals. Arch Phys Med Rehabil 1993;74(2):170-177.

35. Chatwin M, Ross E, Hart N, Nickol AH, Polkey MI, Simonds AK. Cough augmentation with mechanical insufflation/exsufflation in patients with neuromuscular weakness. Eur Respir J 2003;21(3): 502-508.

36. Kang SW, Bach JR. Maximum insufflation capacity: vital capacity and cough flows in neuromuscular disease. Am J Phys Med Rehabil 2000;79(3):222-227.

37. Senent C, Golmard JL, Salachas F, Chiner E, Morelot-Panzini C, Meninger V, et al. A comparison of assisted cough techniques in stable patients with severe respiratory insufficiency due to amyotrophic lateral sclerosis. Amyotroph Lateral Scler 2011;12(1): 26-32.

38. Boitano LJ. Management of airway clearance in neuromuscular disease. Respir Care 2006;51(8):913-922; discussion 922-914.

39. Ishikawa Y, Bach JR, Komaroff E, Miura T, Jackson-Parekh R. Cough augmentation in Duchenne muscular dystrophy. Am J Phys Med Rehabil 2008;87(9):726-730.

40. Trebbia G, Lacombe M, Fermanian C, Falaize L, Lejaille M, Louis A, et al. Cough determinants in patients with neuromuscular disease. Respir Physiol Neurobiol 2005;146(2):291-300.

41. Toussaint M, Pernet K, Steens M, Haan J, Sheers N. Cough augmentation in subjects with duchenne muscular dystrophy: comparison of air stacking via a resuscitator bag versus mechanical ventilation. Respir Care 2016;61(1):61-67.

42. Homnick DN. Mechanical insufflation-exsufflation for airway mucus clearance. Respir Care 2007;52(10):1296-1305; discussion 13061297.

43. Miske LJ, Hickey EM, Kolb SM, Weiner DJ, Panitch HB. Use of the mechanical in-exsufflator in pediatric patients with neuromuscular disease and impaired cough. Chest 2004;125(4):1406-1412.

44. Gómez-Merino E, Sancho J, Marín J, Servera E, Blasco ML, Belda FJ, et al. Mechanical insufflation-exsufflation: pressure, volume, and flow relationships and the adequacy of the manufacturer's guidelines. Am J Phys Med Rehabil 2002;81(8):579-583.

45. Sancho J, Servera E, Marín J, Vergara P, Belda FJ, Bach JR. Effect of lung mechanics on mechanically assisted flows and volumes. Am J Phys Med Rehabil 2004;83(9):698-703.

46. Frigerio P, Longhini F, Sommariva M, Stagni EG, Curto F, Redaelli $\mathrm{T}$, et al. Bench comparative assessment of mechanically assisted cough devices. Respir Care 2015;60(7):975-982.

47. Striegl AM, Redding GJ, Diblasi R, Crotwell D, Salyer J, Carter ER. Use of a lung model to assess mechanical in-exsufflator therapy in infants with tracheostomy. Pediatr Pulmonol 2011;46(3): 211-217.

48. Suri P, Burns SP, Bach JR. Pneumothorax associated with mechanical insufflation-exsufflation and related factors. Am J Phys Med Rehabil 2008;87(11):951-955.

49. Gee SL, Lowe GR, Warren RH. Complications with utilization of positive-pressure devices in a young man with Duchenne muscular dystrophy. Respir Care 2015;60(2):e30-e33.

50. Sancho J, Servera E, Díaz J, Marín J. Efficacy of mechanical insufflation-exsufflation in medically stable patients with amyotrophic lateral sclerosis. Chest 2004;125(4):1400-1405.

51. Andersen T, Sandnes A, Hilland M, Halvorsen T, Fondenes O, Heimdal $\mathrm{JH}$, et al. Laryngeal response patterns to mechanical insufflation-exsufflation in healthy subjects. Am J Phys Med Rehabil 2013;92(10):920-929.

52. Miske LJ, McDonough JM, Weiner DJ, Panitch HB. Changes in gastric pressure and volume during mechanical in-exsufflation. Pediatr Pulmonol 2013;48(8):824-829.

53. Morrow B, Zampoli M, van Aswegen H, Argent A. Mechanical insufflation-exsufflation for people with neuromuscular disorders. Cochrane Database Syst Rev 2013;(12):CD010044.

54. Vianello A, Corrado A, Arcaro G, Gallan F, Ori C, Minuzzo M, Bevilacqua M. Mechanical insufflation-exsufflation improves outcomes for neuromuscular disease patients with respiratory tract infections. Am J Phys Med Rehabil 2005;84(2):83-88; discussion 89-91.

55. Chatwin M, Simonds AK. The addition of mechanical insufflation/ exsufflation shortens airway-clearance sessions in neuromuscular patients with chest infection. Respir Care 2009;54(11):1473-1479.

56. Moran FC, Spittle A, Delany C, Robertson CF, Massie J. Effect of home mechanical in-exsufflation on hospitalisation and life-style in neuromuscular disease: a pilot study. J Paediatr Child Health 2013; 49(3):233-237.

57. Mahede T, Davis G, Rutkay A, Baxendale S, Sun W, Dawkins HJ, et al. Use of mechanical airway clearance devices in the home by people with neuromuscular disorders: effects on health service use and lifestyle benefits. Orphanet J Rare Dis 2015;10:54.

58. Moran FC, Spittle AJ, Delany C. Lifestyle implications of home mechanical insufflation-exsufflation for children with neuromuscular disease and their families. Respir Care 2015;60(7):967-974.

59. Bird FM. Intrapulmonary percussive ventilation (IPV). Flying Physician 1987;30:4-8.

60. Langenderfer B. Alternatives to percussion and postural drainage: a review of mucus clearance therapies: percussion and postural drainage, autogenic drainage, positive expiratory pressure, flutter valve, intrapulmonary percussive ventilation, and high-frequency chest compression with the ThAIRapy Vest. J Cardiopulm Rehabil 1998; 18(4):283-289.

61. Homnick DN, White F, de Castro C. Comparison of effects of an intrapulmonary percussive ventilator to standard aerosol and chest physiotherapy in treatment of cystic fibrosis. Pediatr Pulmonol 1995; 20(1):50-55 


\section{Respiratory Implications of Pediatric Neuromuscular Disease}

62. Natale JE, Pfeifle J, Homnick DN. Comparison of intrapulmonary percussive ventilation and chest physiotherapy: a pilot study in patients with cystic fibrosis. Chest 1994;105(6):1789-1793.

63. Reychler G, Keyeux A, Cremers C, Veriter C, Rodenstein DO, Liistro G. Comparison of lung deposition in two types of nebulization: intrapulmonary percussive ventilation vs jet nebulization. Chest 2004;125(2):502-508.

64. Reychler G, Wallemacq P, Rodenstein DO, Cumps J, Leal T, Liistro G. Comparison of lung deposition of amikacin by intrapulmonary percussive ventilation and jet nebulization by urinary monitoring. J Aerosol Med 2006;19(2):199-207.

65. Toussaint M, Guillet MC, Paternotte S, Soudon P, Haan J. Intrapulmonary effects of setting parameters in portable intrapulmonary percussive ventilation devices. Respir Care 2012;57(5):735-742.

66. Freitag L, Long WM, Kim CS, Wanner A. Removal of excessive bronchial secretions by asymmetric high-frequency oscillations. J Appl Physiol 1989;67(2):614-619.

67. Deakins K, Chatburn RL. A comparison of intrapulmonary percussive ventilation and conventional chest physiotherapy for the treatment of atelectasis in the pediatric patient. Respir Care 2002;47(10): 1162-1167.

68. Chang HK, Weber ME, King M. Mucus transport by high-frequency nonsymmetrical oscillatory airflow. J Appl Physiol 1988; 65(3):1203-1209.

69. King M, Zidulka A, Phillips DM, Wight D, Gross D, Chang HK. Tracheal mucus clearance in high-frequency oscillation: effect of peak flow rate bias. Eur Respir J 1990;3(1):6-13.

70. Sturgess JM, Palfrey AJ, Reid L. The viscosity of bronchial secretion. Clin Sci 1970;38(1):145-156.

71. Bateman JR, Newman SP, Daunt KM, Sheahan NF, Pavia D, Clarke $\mathrm{SW}$. Is cough as effective as chest physiotherapy in the removal of excessive tracheobronchial secretions? Thorax 1981;36(9):683-687.

72. Gross D, Zidulka A, O'Brien C, Wight D, Fraser R, Rosenthal L, King M. Peripheral mucociliary clearance with high-frequency chest wall compression. J Appl Physiol 1985;58(4):1157-1163.

73. Arens R, Gozal D, Omlin KJ, Vega J, Boyd KP, Keens TG, Woo MS. Comparison of high frequency chest compression and conventional chest physiotherapy in hospitalized patients with cystic fibrosis. Am J Respir Crit Care Med 1994;150(4):1154-1157.

74. Warwick WJ, Hansen LG. The long-term effect of high-frequency chest compression therapy on pulmonary complications of cystic fibrosis. Pediatr Pulmonol 1991;11(3):265-271.

75. Crescimanno G, Marrone O. High frequency chest wall oscillation plus mechanical in-exsufflation in Duchenne muscular dystrophy with respiratory complications related to pandemic influenza A/H1N1. Rev Port Pneumol 2010;16(6):912-916.

76. Keating JM, Collins N, Bush A, Chatwin M. High-frequency chestwall oscillation in a noninvasive-ventilation-dependent patient with type 1 spinal muscular atrophy. Respir Care 2011;56(11):18401843.

77. Wampole A, Schroth M, Boriosi J. Survival of a child with spinal muscular atrophy and acute respiratory distress syndrome. Pediatr Pulmonol 2015;50(8):E29-E31.

78. Willis LD, Warren RH. Acute hypoxemia in a child with neurologic impairment associated with high-frequency chest-wall compression. Respir Care 2007;52(8):1027-1029.

79. Yuan N, Kane P, Shelton K, Matel J, Becker BC, Moss RB. Safety, tolerability, and efficacy of high-frequency chest wall oscillation in pediatric patients with cerebral palsy and neuromuscular diseases: an exploratory randomized controlled trial. J Child Neurol 2010; 25(7):815-821

80. Lechtzin N, Wolfe LF, Frick KD. The impact of high frequency chest wall oscillation on healthcare utilization in patients with neuromuscular diseases. Ann Am Thorac Soc 2016;13(6):904-909.
81. Smyth AR, Barbato A, Beydon N, Bisgaard H, de Boeck K, Brand $\mathrm{P}$, et al. Respiratory medicines for children: current evidence, unlicensed use and research priorities. Eur Respir J 2010;35(2):247265.

82. Strickland SL, Rubin BK, Haas CF, Volsko TA, Drescher GS, O'Malley CA. AARC clinical practice guideline: effectiveness of pharmacologic airway clearance therapies in hospitalized patients. Respir Care 2015;60(7):1071-1077.

83. Birnkrant DJ, Panitch HB, Benditt JO, Boitano LJ, Carter ER, Cwik VA, et al. American College of Chest Physicians consensus statement on the respiratory and related management of patients with Duchenne muscular dystrophy undergoing anesthesia or sedation. Chest 2007;132(6):1977-1986.

84. Voelker KG, Chetty KG, Mahutte CK. Resolution of recurrent atelectasis in spinal cord injury patients with administration of recombinant human DNase. Intensive Care Med 1996;22(6):582-584.

85. Fuchs HJ, Borowitz DS, Christiansen DH, Morris EM, Nash ML, Ramsey BW, et al. Effect of aerosolized recombinant human DNase on exacerbations of respiratory symptoms and on pulmonary function in patients with cystic fibrosis: The Pulmozyme Study Group. N Engl J Med 1994;331(10):637-642.

86. Jones AP, Wallis C. Dornase alfa for cystic fibrosis. Cochrane Database Syst Rev 2010;(3):CD001127.

87. Crescimanno G, Marrone O. Successful treatment of atelectasis with dornase alpha in a patient with congenital muscular dystrophy. Rev Port Pneumol 2014;20(1):42-45.

88. O'Donnell AE, Barker AF, Ilowite JS, Fick RB. Treatment of idiopathic bronchiectasis with aerosolized recombinant human DNase I: rhDNase Study Group. Chest 1998;113(5):1329-1334.

89. Elkins MR, Robinson M, Rose BR, Harbour C, Moriarty CP, Marks $\mathrm{GB}$, et al. A controlled trial of long-term inhaled hypertonic saline in patients with cystic fibrosis. N Engl J Med 2006;354(3):229-240.

90. Zhang L, Mendoza-Sassi RA, Klassen TP, Wainwright C. Nebulized hypertonic saline for acute bronchiolitis: a systematic review. Pediatrics 2015;136(4):687-701.

91. Elkins MR, Bye PT. Mechanisms and applications of hypertonic saline. J R Soc Med 2011;104(Suppl 1):S2-S5.

92. Brightling CE. Clinical applications of induced sputum. Chest 2006; 129(5):1344-1348.

93. Hirsh AJ. Altering airway surface liquid volume: inhalation therapy with amiloride and hyperosmotic agents. Adv Drug Deliv Rev 2002; 54(11):1445-1462.

94. King M, Dasgupta B, Tomkiewicz RP, Brown NE. Rheology of cystic fibrosis sputum after in vitro treatment with hypertonic saline alone and in combination with recombinant human deoxyribonuclease I. Am J Respir Crit Care Med 1997;156(1):173-177.

95. Gould NS, Gauthier S, Kariya CT, Min E, Huang J, Brian DJ. Hypertonic saline increases lung epithelial lining fluid glutathione and thiocyanate: two protective CFTR-dependent thiols against oxidative injury. Respir Res 2010;11:119.

96. Reeves EP, Williamson M, O’Neill SJ, Greally P, McElvaney NG. Nebulized hypertonic saline decreases IL-8 in sputum of patients with cystic fibrosis. Am J Respir Crit Care Med 2011;183(11): 1517-1523.

97. Kishioka C, Okamoto K, Kim JS, Rubin BK. Hyperosmolar solutions stimulate mucus secretion in the ferret trachea. Chest 2003; 124(1):306-313

98. Valderramas SR, Atallah AN. Effectiveness and safety of hypertonic saline inhalation combined with exercise training in patients with chronic obstructive pulmonary disease: a randomized trial. Respir Care 2009;54(3):327-333.

99. Shein SL, Gallagher JT, Deakins KM, Weinert DM. Prophylactic use of nebulized hypertonic saline in mechanically ventilated chil- 


\section{Respiratory Implications of Pediatric Neuromuscular Disease}

dren: a randomized blinded pilot study. Respir Care 2016;61(5): 586-592.

100. Bennett WD, Wu J, Fuller F, Balcazar JR, Zeman KL, Duckworth $\mathrm{H}$, et al. Duration of action of hypertonic saline on mucociliary clearance in the normal lung. J Appl Physiol 2015;118(12):14831490 .

101. Bateman ED, Rennard S, Barnes PJ, Dicpinigaitis PV, Gosens R, Gross NJ, et al. Alternative mechanisms for tiotropium. Pulm Pharmacol Ther 2009;22(6):533-542.

102. Kishioka C, Okamoto K, Kim J, Rubin BK. Regulation of secretion from mucous and serous cells in the excised ferret trachea. Respir Physiol 2001;126(2):163-171.

103. Tagaya E, Yagi O, Sato A, Arimura K, Takeyama K, Kondo M, Tamaoki J. Effect of tiotropium on mucus hypersecretion and airway clearance in patients with COPD. Pulm Pharmacol Ther 2016; 39:81-84.

104. Blasco PA, Stansbury JC. Glycopyrrolate treatment of chronic drooling. Arch Pediatr Adolesc Med 1996;150(9):932-935.

105. Garnock-Jones KP. Glycopyrrolate oral solution: for chronic, severe drooling in pediatric patients with neurologic conditions. Paediatr Drugs 2012;14(4):263-269.

106. Thomsen TR, Galpern WR, Asante A, Arenovich T, Fox SH. Ipratropium bromide spray as treatment for sialorrhea in Parkinson's disease. Mov Disord 2007;22(15):2268-2273.

107. Mier RJ, Bachrach SJ, Lakin RC, Barker T, Childs J, Moran M. Treatment of sialorrhea with glycopyrrolate: a double-blind, doseranging study. Arch Pediatr Adolesc Med 2000;154(12):1214-1218.

108. Alves RS, Resende MB, Skomro RP, Souza FJ, Reed UC. Sleep and neuromuscular disorders in children. Sleep Med Rev 2009; 13(2):133-148

109. Arens R, Muzumdar H. Sleep, sleep disordered breathing, and nocturnal hypoventilation in children with neuromuscular diseases. Paediatr Respir Rev 2010;11(1):24-30.

110. Piper A. Sleep abnormalities associated with neuromuscular disease: pathophysiology and evaluation. Semin Respir Crit Care Med 2002;23(3):211-219.

111. Phillipson EA. Control of breathing during sleep. Am Rev Respir Dis 1978;118(5):909-939.

112. Lopes JM, Tabachnik E, Muller NL, Levison H, Bryan AC. Total airway resistance and respiratory muscle activity during sleep. J Appl Physiol Respir Environ Exerc Physiol 1983;54(3):773-777.

113. Tabachnik E, Muller NL, Bryan AC, Levison H. Changes in ventilation and chest wall mechanics during sleep in normal adolescents. J Appl Physiol Respir Environ Exerc Physiol 1981;51(3): 557-564.

114. Dhand UK, Dhand R. Sleep disorders in neuromuscular diseases. Curr Opin Pulm Med 2006;12(6):402-408.

115. Dolmage TE, Avendano MA, Goldstein RS. Respiratory function during wakefulness and sleep among survivors of respiratory and non-respiratory poliomyelitis. Eur Respir J 1992;5(7):864-870.

116. Hsu AA, Staats BA. "Postpolio" sequelae and sleep-related disordered breathing. Mayo Clin Proc 1998;73(3):216-224.

117. Labanowski M, Schmidt-Nowara W, Guilleminault C. Sleep and neuromuscular disease: frequency of sleep-disordered breathing in a neuromuscular disease clinic population. Neurology 1996;47(5): 1173-1180.

118. Katz SL. Assessment of sleep-disordered breathing in pediatric neuromuscular diseases. Pediatrics 2009;123(Suppl 4):S222-S225.

119. Pinard JM, Azabou E, Essid N, Quijano-Roy S, Haddad S, Cheliout-Héraut F. Sleep-disordered breathing in children with congenital muscular dystrophies. Eur J Paediatr Neurol 2012;16(6):619624.

120. Khan Y, Heckmatt JZ. Obstructive apnoeas in Duchenne muscular dystrophy. Thorax 1994;49(2):157-161.
121. Mellies U, Ragette R, Schwake C, Boehm H, Voit T, Teschler H Daytime predictors of sleep disordered breathing in children and adolescents with neuromuscular disorders. Neuromuscul Disord 2003;13(2):123-128.

122. Suresh S, Wales P, Dakin C, Harris MA, Cooper DG. Sleep-related breathing disorder in Duchenne muscular dystrophy: disease spectrum in the paediatric population. J Paediatr Child Health 2005; 41(9):500-503.

123. Smith PE, Calverley PM, Edwards RH. Hypoxemia during sleep in Duchenne muscular dystrophy. Am Rev Respir Dis 1988;137(4): 884-888.

124. O'Brien LM. The neurocognitive effects of sleep disruption in children and adolescents. Child Adolesc Psychiatr Clin N Am 2009; 18(4):813-823.

125. Ragette R, Mellies U, Schwake C, Voit T, Teschler H. Patterns and predictors of sleep disordered breathing in primary myopathies. Thorax 2002;57(8):724-728.

126. Simonds AK, Muntoni F, Heather S, Fielding S. Impact of nasal ventilation on survival in hypercapnic Duchenne muscular dystrophy. Thorax 1998;53(11):949-952.

127. Panitch HB. Diurnal hypercapnia in patients with neuromuscular disease. Paediatr Respir Rev 2010;11(1):3-8.

128. Vianello A, Bevilacqua M, Salvador V, Cardaioli C, Vincenti E. Long-term nasal intermittent positive pressure ventilation in advanced Duchenne's muscular dystrophy. Chest 1994;105(2):445448.

129. Petersen MC, Wolraich M, Sherbondy A, Wagener J. Abnormalities in control of ventilation in newborn infants with myelomeningocele. J Pediatr 1995;126(6):1011-1015.

130. Ho G, Cardamone M, Farrar M. Congenital and childhood myotonic dystrophy: current aspects of disease and future directions. World J Clin Pediatr 2015;4(4):66-80.

131. Guilleminault C, Philip P, Robinson A. Sleep and neuromuscular disease: bilevel positive airway pressure by nasal mask as a treatment for sleep disordered breathing in patients with neuromuscular disease. J Neurol Neurosurg Psychiatry 1998;65(2):225-232.

132. Hill R, Robbins AW, Messing R, Arora NS. Sleep apnea syndrome after poliomyelitis. Am Rev Respir Dis 1983;127(1):129-131.

133. Ward S, Chatwin M, Heather S, Simonds AK. Randomised controlled trial of non-invasive ventilation (NIV) for nocturnal hypoventilation in neuromuscular and chest wall disease patients with daytime normocapnia. Thorax 2005;60(12):1019-1024.

134. White JE, Drinnan MJ, Smithson AJ, Griffiths CJ, Gibson GJ. Respiratory muscle activity and oxygenation during sleep in patients with muscle weakness. Eur Respir J 1995;8(5):807-814.

135. Katz SL, Gaboury I, Keilty K, Banwell B, Vajsar J, Anderson P, et al. Nocturnal hypoventilation: predictors and outcomes in childhood progressive neuromuscular disease. Arch Dis Child 2010; 95(12):998-1003

136. Fromageot C, Lofaso F, Annane D, Falaize L, Lejaille M, Clair B, et al. Supine fall in lung volumes in the assessment of diaphragmatic weakness in neuromuscular disorders. Arch Phys Med Rehabil 2001;82(1):123-128.

137. Finnimore AJ, Jackson RV, Morton A, Lynch E. Sleep hypoxia in myotonic dystrophy and its correlation with awake respiratory function. Thorax 1994;49(1):66-70.

138. Hukins CA, Hillman DR. Daytime predictors of sleep hypoventilation in Duchenne muscular dystrophy. Am J Respir Crit Care Med 2000;161(1):166-170.

139. Bushby K, Finkel R, Birnkrant DJ, Case LE, Clemens PR, Cripe L, et al. Diagnosis and management of Duchenne muscular dystrophy, part 2: implementation of multidisciplinary care. Lancet Neurol 2010;9(2):177-189. 


\section{Respiratory Implications of Pediatric Neuromuscular Disease}

140. Wang CH, Dowling JJ, North K, Schroth MK, Sejersen T, Shapiro $\mathrm{F}$, et al. Consensus statement on standard of care for congenital myopathies. J Child Neurol 2012;27(3):363-382.

141. Wang CH, Bonnemann CG, Rutkowski A, Sejersen T, Bellini J, Battista $\mathrm{V}$, et al. Consensus statement on standard of care for congenital muscular dystrophies. J Child Neurol 2010;25(12):15591581.

142. Katz SL, McKim D, Hoey L, Barrowman N, Kherani T, Kovesi T, et al. Respiratory management strategies for Duchenne muscular dystrophy: practice variation amongst Canadian sub-specialists. Pediatr Pulmonol 2013;48(1):59-66.

143. Paiva R, Krivec U, Aubertin G, Cohen E, Clément A, Fauroux B. Carbon dioxide monitoring during long-term noninvasive respiratory support in children. Intensive Care Med 2009;35(6):1068-1074.

144. Bauman KA, Kurili A, Schmidt SL, Rodriguez GM, Chiodo AE, Sitrin RG. Home-based overnight transcutaneous capnography/pulse oximetry for diagnosing nocturnal hypoventilation associated with neuromuscular disorders. Arch Phys Med Rehabil 2013;94(1): 46-52.

145. Kirk VG, Flemons WW, Adams C, Rimmer KP, Montgomery MD. Sleep-disordered breathing in Duchenne muscular dystrophy: a preliminary study of the role of portable monitoring. Pediatr Pulmonol 2000;29(2):135-140.

146. Passamano L, Taglia A, Palladino A, Viggiano E, D'Ambrosio P, Scutifero M, et al. Improvement of survival in Duchenne muscular dystrophy: retrospective analysis of 835 patients. Acta Myol 2012; 31(2):121-125.

147. Mellies U, Ragette R, Dohna Schwake C, Boehm H, Voit T, Teschler $\mathrm{H}$. Long-term noninvasive ventilation in children and adolescents with neuromuscular disorders. Eur Respir J 2003;22(4):631636.

148. Katz S, Selvadurai H, Keilty K, Mitchell M, MacLusky I. Outcome of non-invasive positive pressure ventilation in paediatric neuromuscular disease. Arch Dis Child 2004;89(2):121-124.

149. Young HK, Lowe A, Fitzgerald DA, Seton C, Waters KA, Kenny $\mathrm{E}$, et al. Outcome of noninvasive ventilation in children with neuromuscular disease. Neurology 2007;68(3):198-201.

150. Bach JR, Bianchi C. Prevention of pectus excavatum for children with spinal muscular atrophy type 1 . Am J Phys Med Rehabil 2003;82(10):815-819.

151. Chatwin M, Bush A, Simonds AK. Outcome of goal-directed noninvasive ventilation and mechanical insufflation/exsufflation in spinal muscular atrophy type I. Arch Dis Child 2011;96(5):426-432.

152. Kennedy JD, Martin AJ. Chronic respiratory failure and neuromuscular disease. Pediatr Clin North Am 2009;56(1):261-273, xii.

153. Laub M, Berg S, Midgren B. Symptoms, clinical and physiological findings motivating home mechanical ventilation in patients with neuromuscular diseases. J Rehabil Med 2006;38(4):250-254.

154. Raphael JC, Chevret S, Chastang C, Bouvet F. Randomised trial of preventive nasal ventilation in Duchenne muscular dystrophy: French Multicentre Cooperative Group on Home Mechanical Ventilation Assistance in Duchenne de Boulogne Muscular Dystrophy. Lancet 1994;343(8913):1600-1604
155. Bach JR, Niranjan V, Weaver B. Spinal muscular atrophy type I: a noninvasive respiratory management approach. Chest 2000;117(4): 1100-1105.

156. Sritippayawan S, Kun SS, Keens TG, Davidson Ward SL. Initiation of home mechanical ventilation in children with neuromuscular diseases. J Pediatr 2003;142(5):481-485

157. Benditt JO. Full-time noninvasive ventilation: possible and desirable. Respir Care 2006;51(9):1005-1012; discussion 1012-1005.

158. Boitano LJ, Benditt JO. An evaluation of home volume ventilators that support open-circuit mouthpiece ventilation. Respir Care 2005; 50(11):1457-1461.

159. Khirani S, Ramirez A, Delord V, Leroux K, Lofaso F, Hautot S, et al. Evaluation of ventilators for mouthpiece ventilation in neuromuscular disease. Respir Care 2014;59(9):1329-1337.

160. Soudon P, Steens M, Toussaint M. A comparison of invasive versus noninvasive full-time mechanical ventilation in Duchenne muscular dystrophy. Chron Respir Dis 2008;5(2):87-93.

161. Toussaint M, Steens M, Wasteels G, Soudon P. Diurnal ventilation via mouthpiece: survival in end-stage Duchenne patients. Eur Respir J 2006;28(3):549-555.

162. Britton D, Benditt JO, Hoit JD. Beyond tracheostomy: noninvasive ventilation and potential positive implications for speaking and swallowing. Semin Speech Lang 2016;37(3):173-184.

163. Chatwin M, Nickol AH, Morrell MJ, Polkey MI, Simonds AK. Randomised trial of inpatient versus outpatient initiation of home mechanical ventilation in patients with nocturnal hypoventilation. Respir Med 2008;102(11):1528-1535.

164. Bach JR, Tran J, Durante S. Cost and physician effort analysis of invasive vs. noninvasive respiratory management of Duchenne muscular dystrophy. Am J Phys Med Rehabil 2015;94(6):474-482.

165. Carron M, Freo U, BaHammam AS, Dellweg D, Guarracino F, Cosentini R, et al. Complications of non-invasive ventilation techniques: a comprehensive qualitative review of randomized trials. Br J Anaesth 2013;110(6):896-914.

166. Kelly CR, Higgins AR, Chandra S. Videos in clinical medicine: noninvasive positive-pressure ventilation. N Engl J Med 2015; 372(23):e30

167. Fauroux B, Lavis JF, Nicot F, Picard A, Boelle PY, Clément A, Vazquez MP. Facial side effects during noninvasive positive pressure ventilation in children. Intensive Care Med 2005;31(7):965969.

168. Li KK, Riley RW, Guilleminault C. An unreported risk in the use of home nasal continuous positive airway pressure and home nasal ventilation in children: mid-face hypoplasia. Chest 2000;117(3): 916-918.

169. Villa MP, Pagani J, Ambrosio R, Ronchetti R, Bernkopf E. Midface hypoplasia after long-term nasal ventilation. Am J Respir Crit Care Med 2002;166(8):1142-1143.

170. Ramirez A, Delord V, Khirani S, Leroux K, Cassier S, Kadlub N, et al. Interfaces for long-term noninvasive positive pressure ventilation in children. Intensive Care Med 2012;38(4):655-662.

171. Simonds AK. Respiratory support for the severely handicapped child with neuromuscular disease: ethics and practicality. Semin Respir Crit Care Med 2007;28(3):342-354.

\section{Discussion}

Berlinski: I have a couple of questions. The first is regarding the use of IPV. One of the issues we have is that although it might be paid for by a third party payer, the overhaul that this de- vice requires every year to function properly is not paid. So even if we can get a charity to buy the machine for the family, it's like having a car without money for maintenance or oil changes, and you really don't know what quality of therapy you end up delivering. I don't know if that's a national problem. I would like you to comment on that. The second is on the use of sodium bicarbonate that some physicians use to break down tenacious mucus. I would like your perspective on that. 
Panitch: The question about servicing IPV machines I think falls under a larger umbrella covering lots of homecare equipment. For instance, homecare companies receive a monthly rental fee for NIV machines or CPAP devices, but after a while, the machine is paid for, and the home care company doesn't get reimbursed for it any longer. At that point, the cost of caring for the machine or checking of patients by the home care company isn't covered, and it's a problem. On the other hand, some of the reimbursement schemes result in paying several times the cost of the machine with the idea being that patients can get some of those monitoring services from the durable medical equipment company. I think it's an issue of how home care companies are reimbursed, and I don't think there's a very thoughtful scheme for how we can service these devices as they get older. I do think it's a national and probably an international problem. As far as sodium bicarbonate goes, we don't use it at our institution, and I don't have any experience in its use as a mucolytic agent. I have not seen anything in the literature that addresses the use of bicarb as an inhaled mucolytic. I know that it's sometimes instilled into an artificial airway for bleeding, but I haven't seen the data to support that.

Stokes: Howard, nice talk. I actually asked Bruce Rubin about sodium bicarbonate recently because we've used it some, and I wondered if he had any thoughts about it. He has a nice review in a previous Journal Conference about mucolytic agents, and he couldn't support use of sodium bicarbonate. ${ }^{1}$ But I think it's something that could be studied, particularly combined with hypertonic saline. Say I'm the CEO of a health insurance company and I'm only going to give you $\$ 10,000$ for your neuromuscular patient, so you have to pick one. Either the vest, IPV, or in-exsufflator. Which one are you going to pick?
Panitch: I'm going to pick the one that the patient will use. I think that goes along with any airway clearance regimen, whether you're talking about cystic fibrosis or neuromuscular disease. If the patient won't use it, it's an expensive paperweight or doorstop. I do think, in general, the in-exsufflator is probably our go-to device. It's an extractor of secretions, and it helps when people have a weak cough. But if children also have a propensity to generate lots of secretions, then I think a mobilization device makes sense. If you can combine those two in the proper patient group, you can save a lot of money because the cost of those 2 pieces of equipment is dwarfed by a single hospitalization, especially if the child has to go to the ICU. So if we had more data like Lechtzin's ${ }^{2}$ that suggest that the proper use of that type of equipment will reduce costs, we'll have a different conversation where I say I'm going to save you money if you will support my patients and make it possible for them to stay home.

Stokes: In the absence of data showing that the two together are better than one, it's going to be tough.

Panitch: But I think that every publication that looks at mobilization, whether it's the vest or IPV or mucolytic agents, cautions that you have to be able to clear the central airways of secretions. If you only have a device that mobilizes secretions into the central airways and you can't help the patient extract the mucus from the airways, you could cause life-threatening obstruction.

Cheifetz: Excellent presentation. Thank you, Howie. On the topic of NIV, I have a series of related questions. For continuous NIV, for how young of a patient do you find that approach to be successful? The next, based on patient age, what challenges or lack of challenges have you encountered with the interfaces? Lastly, in terms of the interfaces, how signif- icant of a problem is injury to the skin integrity? I know that in the acute care setting, we have real problems with all of these issue, but in the home environment, what is your experience?

Panitch: I'm not sure I can give you an age. We've had situations with children $<6$ months of age with severe SMA I whose parents weren't sure whether they wanted to go the route of tracheostomy, whom we supported with NIV $24 \mathrm{~h} /$ day. That was in an age where we had fewer choices of interfaces, and one patient who comes to mind had problems with nasal bridge breakdown that really made us get very creative in terms of nasal interfaces. In the United States, we don't have the same capabilities for obtaining custom masks that people in Europe do to help avoid some of the problems with skin breakdown. We typically will try to get at least 2 different mask styles for our patients to alternate pressure points, especially for those who are using masks for $16 \mathrm{~h}$ or more per day. If the patient is hospitalized, we have a rigorous protocol for skin checks every $4 \mathrm{~h}$, and if there is redness that doesn't blanch or that is persistent, we intervene. In the hospital, we use Mepilex as a barrier; we don't do that at home. But I also find that parents know very well how to place a mask on their child, and they are better at avoiding the skin problems that we see in the hospital. In addition, the kids are sick when they come into the hospital, so it's not an equivalent comparison: sick patients can have poorer perfusion, and they may require higher pressures that could compromise skin integrity as well. The other thing that is a real problem, especially in the youngest children, is that we watch their faces flatten as a result of prolonged application of pressure to the facial structures. We talk to families about that. I've cared for toddlers with myotubular myopathy, for instance, where you see them develop a concave face. That's been described in the literature, where the con- 
stant pressure on the mid-face causes flattening.

Cheifetz: I will reiterate what I have said to the folks in industry for years and will use this forum as an additional prompt: Although the number of interfaces that we have available for infants and children has improved in recent years, we really need additional NIV products to provide a wider range of choices for pediatric patients so that we as a community can take the great work that is occurring (as you have done an excellent job of outlining) and advance it further.

Panitch: I could not agree more.

Berlinski: With the advancement of personalized medicine and use of 3D scanning of the face, especially for patients with craniofacial abnormalities, the future will allow us to be able to customize the interface. Many times, the inability to properly ventilate a patient due to lack of an appropriate interface results in tracheostomy placement.

Panitch: I agree.

\section{REFERENCES}

1. Rubin BK. Mucolytics, expectorants, and mucokinetic medications. Respir Care 2007;52(7):859-865

2. Lechtzin N, Wolfe LF, Frick KD. The impact of high frequency chest wall oscillation on healthcare utilization in patients with neuromuscular diseases. Ann Am Thorac Soc 2016;13(6):904-909. 